\title{
Can Online Delivery Increase Access to Education?
}

\section{Citation}

Goodman, Joshua, Julia Melkers, and Amanda Pallais. 2016. "Can Online Delivery Increase Access to Education?" HKS Faculty Research Working Paper Series RWP16-035.

\section{Published Version}

https://research.hks.harvard.edu/publications/getFile.aspx?ld=1435

\section{Permanent link}

http://nrs.harvard.edu/urn-3:HUL.InstRepos:37093804

\section{Terms of Use}

This article was downloaded from Harvard University's DASH repository, and is made available under the terms and conditions applicable to Other Posted Material, as set forth at http:// nrs.harvard.edu/urn-3:HUL.InstRepos:dash.current.terms-of-use\#LAA

\section{Share Your Story}

The Harvard community has made this article openly available.

Please share how this access benefits you. Submit a story.

\section{Accessibility}


NBER WORKING PAPER SERIES

CAN ONLINE DELIVERY INCREASE ACCESS TO EDUCATION?

Joshua Goodman

Julia Melkers

Amanda Pallais

Working Paper 22754

http://www.nber.org/papers/w22754

\author{
NATIONAL BUREAU OF ECONOMIC RESEARCH \\ 1050 Massachusetts Avenue \\ Cambridge, MA 02138 \\ October 2016
}

We thank Zvi Galil, Alan Glass, Michael Terrazas, and David White for supporting this research, explaining how OMSCS and its admissions process works, and sharing data. For helpful comments, we thank David Autor and Larry Katz, as well as seminar participants at Harvard, MIT, Columbia, University of Mannheim, CESifo, UIUC, University of Connecticut, University of Virginia, Louisiana State University, NYU, Stanford, Carleton, APPAM and AEFP. Carlos Paez, Melanie Rucinski and Tianlog Xu provided excellent research assistance. The views expressed herein are those of the authors and do not necessarily reflect the views of the National Bureau of Economic Research.

NBER working papers are circulated for discussion and comment purposes. They have not been peer-reviewed or been subject to the review by the NBER Board of Directors that accompanies official NBER publications.

(C) 2016 by Joshua Goodman, Julia Melkers, and Amanda Pallais. All rights reserved. Short sections of text, not to exceed two paragraphs, may be quoted without explicit permission provided that full credit, including $\odot$ notice, is given to the source. 
Can Online Delivery Increase Access to Education?

Joshua Goodman, Julia Melkers, and Amanda Pallais

NBER Working Paper No. 22754

October 2016

JEL No. I20,I23,J2,J24

\begin{abstract}
$\underline{\text { ABSTRACT }}$ for populations who would not otherwise pursue education.

Joshua Goodman

Harvard Kennedy School

79 JFK Street

Cambridge, MA 02138

and NBER

joshua_goodman@hks.harvard.edu

Julia Melkers

School of Public Policy

Georgia Institute of Technology

685 Cherry Street Atlanta, GA 30332

julia.melkers@pubpolicy.gatech.edu

Amanda Pallais

Department of Economics

Harvard University

Littauer Center

Cambridge, MA 02138

and NBER

apallais@ fas.harvard.edu
\end{abstract}

Though online technology has generated excitement about its potential to increase access to education, most research has focused on comparing student performance across online and inperson formats. We provide the first evidence that online education affects the number of people pursuing formal education. We study Georgia Tech's Online M.S. in Computer Science, the earliest model to combine the inexpensive nature of online education with a highly-ranked degree program. Regression discontinuity estimates exploiting an admissions threshold unknown to applicants show that access to this online option substantially increases overall enrollment in formal education, expanding the pool of students rather than substituting for existing educational options. Demand for the online option is driven by mid-career Americans. By satisfying large, previously unmet demand for mid-career training, this single program will boost annual production of American computer science master's degrees by about seven percent. More generally, these results suggest that low-cost, high-quality online options may open opportunities 


\section{Introduction}

Online coursework has been heralded as potentially transformative for higher education, possibly lowering costs of delivery and increasing access for disadvantaged students. From 2002 through 2012, the number of online bachelor's degrees awarded rose from 4,000 to 75,000, or five percent of all U.S. bachelor's degrees issued that year (Deming et al., 2015). The federal government estimates that 27 percent of college students were taking at least one course online as of 2013, the most recent year for which data exists ${ }^{1}$ Though online education is increasingly prevalent, we know relatively little about the longer run implications of the existence of this new form of human capital development (McPherson and Bacow, 2015).

This paper provides the first evidence on whether online education can improve access to education, a key question in evaluating online education's overall impact. Does online education simply substitute for in-person education or does it instead expand access to students who would not otherwise have enrolled in an educational program? Existing research largely compares student performance in online and in-person classes, often by randomly assigning students to one format or the other conditional on already having enrolled. The online format generally leads to worse learning outcomes (Joyce et al., 2015; Alpert et al., 2016; Krieg and Henson, 2016), particularly for academically weaker students such as those in community colleges ( $\mathrm{Xu}$ and Jaggars, 2014) and for-profit colleges (Bettinger et al., 2015). In some settings, students do equally well across both formats, raising the possibility that the online format may nonetheless be a cost effective delivery mechanism (Figlio et al., 2013; Bowen et al., 2014).

Though the body of research on the pedagogical efficacy of the online format is growing, no prior research on online education has addressed whether the existence of online options increases the number of people obtaining formal education. This is in part because the ubiquity of such options makes it difficult to construct convincing counterfactuals. Understanding the impact of online education depends, however, on whether online classes replace in-person classes or generate additional human capital investment.

\footnotetext{
${ }^{1}$ See Table 311.15 of the 2014 Digest of Education Statistics, published by the U.S. Department of Education's National Center for Education Statistics.
} 
We provide evidence on this by examining the earliest educational model to combine the inexpensive nature of online education with a degree program from a highly-ranked institution. Specifically, we study the new Online Master of Science in Computer Science (OMSCS) offered by the Georgia Institute of Technology (Georgia Tech) and developed in partnership with Udacity and AT\&T. In spring 2014, Georgia Tech's Computer Science Department, which is regularly ranked in the top ten in the United States, started enrolling students in a fully online version of its highly regarded master's degree. The online degree costs about $\$ 7,000$, less than one-sixth of the $\$ 45,000$ out-of-state students pay for Georgia Tech's in-person computer science master's degree (MSCS). Program price and admissions criteria were set in part to attract a much larger number of students than the in-person program without compromising the quality of the degree.

Importantly, the degree OMSCS students earn is not labeled "online" and is in name fully equivalent to the in-person degree. As a result, the reputation and labor market value of Georgia Tech's in-person degree now at least partially depend on the extent to which Georgia Tech can ensure that the quality of its graduates does not differ substantially across the two formats. In an attempt to address the quality concerns that online education raises, Georgia Tech designed OMSCS such that its courses are online versions of the same courses in-person students take, designed by the same faculty teaching those courses, and graded using the same standards.

We first document where demand for this model of online education comes from by comparing the online and in-person applicant pools, as both programs lead to the same degree but through different formats. We find large demand for the online program, which is now the nation's largest master's degree program in computer science. Importantly, there is nearly no overlap between the applicant pools to these two programs, with few individuals applying to both. The average inperson applicant is a 24-year old non-American recently out of college, whereas the average online applicant is a 34-year old mid-career American. Eighty percent of those admitted to the online program accept those offers and enroll, suggesting few find compelling alternative educational options. Large demand from a mid-career population uninterested in its in-person equivalent and a high matriculation rate both suggest the online program is drawing in students who would not otherwise enroll elsewhere. 
Next, we rigorously estimate whether this online option expands access to formal education for students who would not otherwise enroll, thus increasing the number of students participating in higher education. To do so, we utilize quasi-random variation in admission to OMSCS to determine the extent to which access to the online option substitutes for enrollment in other programs. We exploit the fact that capacity constraints for the first applicant cohort led to the program's admission officer reading applications in descending order of undergraduate GPA until he had identified about 500 applicants to which immediate admission was offered. As a result, such offers were made only to those with a GPA of at least 3.26, a threshold that was arbitrary and unknown to applicants. The officer eventually read all of the applications and some of those below the threshold were offered deferred admission. A regression discontinuity design shows this admissions process created at the threshold a roughly 20 percentage point difference in the probability of admission to the online program.

With National Student Clearinghouse data that tracks enrollment in any U.S. formal higher education, we use a regression discontinuity design to compare enrollment outcomes for applicants just above and below that threshold, two groups who differ only in their access to this online option. We find a roughly 20 percentage point difference in the probability of eventually enrolling in the online program, the magnitude of which suggests that roughly all of the marginal admits ultimately matriculate ${ }^{2}$ Importantly, we show that very few applicants to OMSCS enroll in other, non-OMSCS programs. Those just below the admission threshold are no more likely to enroll elsewhere than those just above it, implying that access to the online program does not substitute for other educational options. Such access thus substantially increases the number of students enrolling at all. The higher education market appears to have been failing to meet demand for this online option.

Early evidence also suggests that this online program is delivering a relatively high-quality educational experience. To test whether students pursuing the degree online were learning as much as those pursuing it in person, Georgia Tech blindly graded final exams for online and inperson students taking the same course from the same instructor. The online students slightly

\footnotetext{
${ }^{2}$ The difference in OMSCS enrollment at the discontinuity is not due to differential likelihood of enrolling in OMSCS conditional on admission. On both sides of the discontinuity, 80 percent of admitted students enroll in the program.
} 
outperformed the in-person students (Goel and Joyner. 2016). OMSCS students are also persisting at rates substantially higher than students in nearly all MOOCs and higher than in many online degree programs. Among those students who started OMSCS in 2014, 62 percent remain enrolled two years later, apparently on track to complete their degrees. This is very likely a lower bound on completion rates given that over 25 percent of students who take a semester off from the program re-enroll in subsequent semesters. Given the nearly 1,200 Americans enrolling each year in OMSCS and assuming only those 62 percent graduate, this implies production of at least 725 new American computer science master's degrees holders annually. Roughly 11,000 Americans earn their master's degree in computer science each year, implying that this single program will boost annual national production of American computer science master's degrees by about seven percent.

That OMSCS appears to be filling a gap in the higher education market may explain why the announcement of the program in 2013 garnered such extensive media attention. OMSCS was described as the first large-scale program offered by a highly-ranked department, priced much lower than its in-person equivalent and culminating in a prestigious graduate degree. Prior models of online education had involved highly-ranked institutions offering online degrees as costly as their in-person equivalents, lower-ranked institutions offering inexpensive degrees with low labor market returns (Deming et al. 2016), or free massive online open courses (MOOCs) with unclear returns and very high attrition rates (Perna et al., 2013: Banerjee and Duflo, 2014). Because OMSCS' price-quality pairing had not been previously seen in online education, the New York

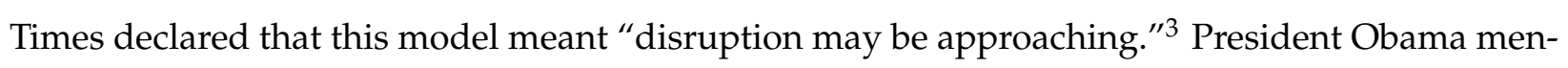
tioned OMSCS in an August 2013 speech on college affordability and again in March 2015 while visiting Georgia Tech, describing the program as a model for "innovative ways to increase value" in higher education. 4

The low-cost, high-quality model pursued by OMSCS appears to be growing in importance. In spring of 2016, inspired in part by OMSCS, the University of Illinois at Urbana-Champaign (UIUC)

\footnotetext{
${ }^{3}$ T. Lewin (2013), "Master's Degree Is New Frontier of Study Online" New York Times, August 17.

${ }^{4}$ B. Obama (2015), "Remarks by the President Announcing Student Aid Bill of Rights." March 10 https:/ / www.whitehouse.gov/the-press-office/2015/03/10/remarks-president-announcing-student-aid-bill-rights.
} 
began enrolling students in its "iMBA" program, a fully-online version of its highly-regarded MBA. The degree costs about $\$ 22,000$, roughly one-third the cost of the in-person MBA offered by UIUC and similarly-ranked institutions. Yale University is currently developing a fully online version of its Master of Medical Science degree for physician assistants. In the fall of 2016, over a dozen highly ranked universities affiliated with the EdX consortium started by Harvard and MIT announced plans to offer micro-master's degrees. Such degrees will be open to any student willing to pay a total of roughly $\$ 1,000$ for exam proctoring at the end of each course and will consist of between one-quarter and one-half of the courses in a traditional version of each degree. Examples of such degrees include supply chain management from MIT, artificial intelligence from Columbia University, and social work from the University of Michigan at Ann Arbor: $5^{5}$ That more highlyranked institutions appear to be entering the market for inexpensive online degrees suggests our results may be increasingly relevant to the future of online education.

The remainder of the paper proceeds as follows. In Section 2, we describe the OMSCS program in more detail, describe the available data, and descriptively compare the applicant pools to the in-person and online programs. In Section 3, we present regression discontinuity estimates of the impact of access to online education on overall enrollment. In Section 4, we discuss the implications of our findings. We argue that the single program studied here will likely increase the number of Americans earning computer science master's degrees by about seven percent. We also discuss the external validity of these findings, as well as concerns about the quality of education delivered by the online program.

\section{Context and Data}

\subsection{The OMSCS Degree Program}

OMSCS courses are offered through a platform designed by Udacity, one of the largest providers of massive open online courses $4^{6}$ To earn their degree, OMSCS students must complete 10 courses,

\footnotetext{
${ }^{5}$ J. Young (2016), “Online Micro-Master's Programs Extend Their Reach” Chronicle of Higher Education, September 20.

${ }^{6}$ To create the OMSCS program, Georgia Tech partnered with Udacity and AT\&T, the latter of which provided startup funding.
} 
specializing in either computational perception and robotics, computing systems, interactive intelligence, or machine learning. Students who have taken two foundational courses can take up to three classes per semester, while other students can take only two at a time. The typical student takes one or two courses each semester, so that expected time to graduation is six to seven semesters, which can include summer terms. In order to maintain educational quality, the online courses use similar assignments and grading standards as their in-person counterparts. Consistent with the OMSCS degree being at least nominally equivalent to the in-person degree, OMSCS is accredited because the accreditor considers it equivalent to the in-person program.

Though deadlines for submitting assignments are the same as the in-person courses, one major difference is that all lecture-watching and other learning experiences are asynchronous, meaning that there is no fixed time during which a student must be online. All content is posted at the start of the semester so that students may proceed at a pace of their choosing. Students schedule their exams within a specified window and are monitored to guard against cheating. Most interaction happens in online forums where students post questions and receive answers from fellow students, teaching assistants, or faculty members. Faculty members interact with students in online office hours, though online forums are typically run by the head teaching assistant. Feedback on assignments comes from teaching assistants, many of whom are current MSCS or OMSCS students and each of whom serves approximately 50 students.7

AT\&T provided roughly $\$ 4,000,000$ in start-up funds to supplement GA Tech's own initial investment. Much of that funded production of the roughly 30 courses OMSCS offers, each of which initially cost about $\$ 300,000$ to produce, though production costs have since dropped to under $\$ 200,000$. Such costs reflect the fact that OMSCS does not record and re-broadcast in-person lectures as some online courses do, but instead produces original videos and other materials for each course. Individual faculty members are paid $\$ 20,000$ for initially creating a course and $\$ 10,000$ each time they teach the course, which many of them continue to do. In 2015, OMSCS had net revenues of about $\$ 2,000,000$ and by fall 2016 had returned the Computer Science Department's

\footnotetext{
${ }^{7}$ One teaching assistant is not human. Professor Ashok Goel, who teaches a course entitled "Knowledge Based Artificial Intelligence," created a virtual teaching assistant named Jill, based on artificial intelligence technologies adapted from IBM's Watson platform. Jill regularly answered students' questions and was only revealed to them as virtual late in the semester.
} 
initial investment in the program.

To make OMSCS accessible to a wider range of applicants than its in-person counterpart, its admissions website describes as "preferred qualifications" having a B.A. in computer science or a related field with an undergraduate GPA of 3.0 or higher 8 Such qualifications do not guarantee admission and, as the website notes, "applicants who do not meet these criteria will be evaluated on a case-by-case basis." The admissions website to the in-person program describes a GPA of 3.0 as a "desirable minimum" and notes that "most candidates score higher." MSCS also requires submission of GRE scores, which OMSCS does not. Whereas MSCS has one cohort of applicants each year who apply to start in the fall, OMSCS has two applicant cohorts each year as students can begin their coursework in either the fall or the spring. The first OMSCS enrollees began their coursework in the spring of 2014.

\subsection{Data}

We have data from Georgia Tech's Computer Science Department on all applicants to OMSCS's first six cohorts, who started their courses in spring 2014, fall 2014, spring 2015, fall 2015, spring 2016, and fall 2016. We also have data on four cohorts of applicants to MSCS, those applying to start classes in each fall from 2013 through 2016. For each applicant, we have basic self-reported demographic information including age, gender, race/ethnicity, and citizenship. Applicants also report their postsecondary educational history, including the name of each college attended, their GPA at that college, and the field and type of any degree earned. Applicants report the name of their employer if employed at the time of application. We also observe whether a given applicant was ever admitted to or enrolled in OMSCS or MSCS.

We merge all applicants' data to the National Student Clearinghouse (NSC), an organization that tracks enrollment at post-secondary institutions throughout the United States. The NSC identifies which, if any, institution a student is enrolled in at any moment in time, allowing us to track the educational trajectories of students who enroll in Georgia Tech and other institutions $9^{9}$ NSC

\footnotetext{
${ }^{8}$ As we describe below, our regression discontinuity analysis uses a different GPA cutoff that affected the probability of admission but was unknown to applicants.

${ }^{9}$ Though the NSC also records degree completion, it is too early to measure this given that most initial OMSCS enrollees have not yet been enrolled for the two to three years expected for graduation.
} 
coverage rates for undergraduates in Georgia are around 95 percent and generally above 90 percent in other states (Dynarski et al. 2015). Though less is known about graduate student coverage rates, we show that a very high fraction of MSCS applicants are observed enrolling in institutions other than Georgia Tech, suggesting widespread coverage of master's degree students. Importantly, we do observe many for-profit and nonprofit institutions that primarily offer online coursework, such as the University of Phoenix and Western Governor's University. We supplement this with data from the National Science Foundation on the full population of students earning computer science master's degrees in the United States in 2013, the most recent year available.

\section{Descriptive Comparison of Applicant Pools}

To document where demand for OMSCS comes from, we describe the characteristics of the OMSCS applicant pool and compare them to the characteristics of the MSCS applicant pool. Because both programs culminate in the same nominal degree, we view such a comparison as controlling for the degree sought. As such, we argue that differences in the applicant pools between these programs are largely due to differences in the programs' costs and methods of curriculum delivery.

Demand for the online program is large, as seen in panel A of Table 1. OMSCS attracts over 3,400 applicants annually, about twice as many as its in-person equivalent. This is not due simply to large pent-up demand, as the most recent applicant cohort is larger than all but the first cohort, which contained many AT\&T employees ${ }^{10}$ OMSCS admits 61 percent of those applicants, almost five times the 13 percent admission rate for the in-person program. OMSCS is thus less selective and more open than its in-person counterpart, as program designers intended.

Eighty percent of those admitted to the online program enroll, so that each year nearly 1,700 students begin a computer science master's degree through OMSCS, more than 10 times as many who begin a degree through MSCS. This makes OMSCS the largest computer science master's degree program in the United States, and possibly the world. By way of comparison, the NSF estimates that U.S. institutions issued about 21,000 computer science master's degrees in 2013. If

\footnotetext{
${ }^{10}$ See columns $1-6$ of Table A.1.
} 
all OMSCS enrollees were to complete their degrees, OMSCS would be responsible for the production of eight percent of all computer science master's degrees in the country. The nearly 1,200 annual American enrollees in OMSCS would represent over ten percent of all Americans earning such degrees.

Two descriptive facts suggest that demand for the online program comes from a different population than demand for the in-person program. First, in our data, fewer than 0.2 percent of the nearly 18,000 applicants to either program applied to both programs, suggesting that students view these programs as distinct educational products. Second, as panel B in Table 1 shows, the applicant pools to the two programs look very different, particularly in terms of nationality and age ${ }^{11}$

The online program attracts a much more American demographic than does the in-person program. About 70 percent of the online applicants are U.S. citizens, compared to 8 percent of in-person applicants. Figure 1 shows the distribution of citizenship across the two pools. The vast majority of in-person applicants are citizens of India (nearly 70 percent) or China (nearly 20 percent). After admissions and enrollment decisions, the fraction of in-person enrollees who are U.S. citizens rises to 26 percent. Even so, over half of that student body are Indian or Chinese citizens. Panel B shows that fewer than 10 percent of applicants to the online program are Indian or Chinese citizens, proportions that do not change substantially with admissions and enrollment decisions. That international applicants show stronger demand for the in-person program suggests such students may value the opportunity to be physically present in the U.S., which admission to an online program does not grant $\sqrt{12}$ That over 70 percent of online program enrollees are U.S. citizens makes that pool substantially more American than the national pool of those completing computer science master's degrees, of whom 52 percent are U.S. citizens.

The online program attracts a substantially older demographic than does the in-person program. Online applicants are on average 34 years old, compared to an average age of 24 for in-

\footnotetext{
${ }^{11}$ Table A.1 shows the characteristics of individual cohorts of applicants. None of the demographic facts highlighted here change substantially over the observed time period.

${ }^{12}$ Low international awareness of OMSCS' existence may explain a small portion of their proportionally stronger demand for the in-person program, as Table A.1 shows that the international composition of the applicant pool has very slowly increased over time, perhaps because such awareness has increased.
} 
person applicants. Figure 2 shows the age distribution of applicants to the two programs. Over 75 percent of in-person applicants are 25 years old or younger and over 95 percent are 30 or younger. Nearly no one older than 30 applies to the in-person program. The opposite is true of the online program. Only 10 percent of online applicants are 25 or younger and fewer than 30 percent are between 25 and 30. The majority of applicants are over 30 years old, with substantial representation of those in their 40s and 50s. This remains true if the sample is limited to those admitted or to those who enroll.

Whereas the in-person program attracts applicants straight out of college or early in their careers, the online program attracts an older population largely in the middle of their careers. Nearly ninety percent of online applicants list a current employer, relative to under 50 percent of in-person applicants ${ }^{13}$ Table 2 shows more detail about online applicants' employment, listing the top 25 employers represented in their applications. Because of its corporate sponsorship of the development of OMSCS, AT\&T is by far the largest such employer 14 Well-represented in the list are technology giants (Microsoft, Google, Amazon, Apple), military branches (Air Force, Army, Navy), defense contractors (Lockheed Martin, Raytheon, Northrop Grumman, Boeing), and financial and consulting firms (Bank of America, Accenture). Such firms, with more than 25 employees applying to OMSCS, comprise less than one-fourth of the applicant pool. Firms with 2 to 25 applicants comprise one-fifth of the applicant pool. Remarkably, nearly half of applicants to OMSCS appear to be the only employee from their firms applying to the program, suggesting that demand for such training is widespread and not simply concentrated among a few large firms.

The online and in-person applicant and enrollee pools look fairly similar in terms of gender and race, particularly when the sample is limited to U.S. citizens. Only 13 percent of U.S. citizen online applicants are female, a proportion quite similar to the percentage in the in-person program 15 Among U.S. citizens, the online applicant pool is 64 percent white, 17 percent black

\footnotetext{
${ }^{13}$ Employment information is missing for the 2013 MSCS applicants, so the 50 percent figure is based on 2014-16 MSCS applicants.

${ }^{14}$ As seen in Table A.1 this is driven largely by the first cohort of applicants, of whom 23 percent were from AT\&T. That proportion drops to fewer than 10 percent in subsequent cohorts. None of the demographic facts discussed here change meaningfully when AT\&T employees are removed from the sample.

${ }^{15}$ Among all applicants, the in-person program has a higher proportion of female applicants due to the fact that Indian and Chinese applicants are more likely to be female than are American applicants.
} 
or Hispanic, and 15 percent Asian, proportions roughly similar to the in-person applicant pool. There is little evidence of differential gender or racial diversity by program type. Other forms of diversity, such as socioeconomic status and academic skill, are hard to evaluate because our application data contain no information on family background and no objective measures of academic skill that are comparable across the two applicants pools ${ }^{16}$

We can, however, use characteristics of applicants' undergraduate institutions as proxies for applicants' family backgrounds and academic skills. To do so, we use data from the Integrated Postsecondary Education Data System (IPEDS) to characterize applicants by the U.S. colleges they attended ${ }^{17}$ Table 3 shows clear differences across the two applicant pools. Online applicants come from colleges where the average student's SAT math score is 30 points, or about 0.2 standard deviations, lower than students from in-person applicants' colleges. Online applicants' colleges have a higher proportion of low income students, as well as a substantially lower six-year graduation rate. Differences among admitted students and enrollees are of similar magnitude. This suggests that the online program attracts applicants who are from more economically disadvantaged backgrounds and who are academically weaker on average than their in-person counterparts. Online applicants also have a more diverse set of college majors, as they are much less likely than inperson applicants to have majored in computer science. Instead, they are more likely to have majored in engineering, mathematics, physical sciences, and even social sciences and humanities.

The descriptive comparison of the two applicant pools thus provides three pieces of evidence that together are consistent with the possibility that OMSCS represents a new educational product for which there is currently no close substitute in the formal higher education market. First, though the two programs culminate in the same degree, there is nearly no overlap in the populations interested in these educational options. The typical applicant to the in-person program is a 24-year old recent college graduate from India, whereas the typical applicant to the online program is a 34-year old currently-employed American. Second, demand from Americans for

\footnotetext{
${ }^{16}$ Unlike the in-person program, the online program does not require applicants to submit GRE scores.

${ }^{17}$ We use IPEDS data from 2005, roughly the average year of college graduation for online applicants. Our results are not sensitive to this choice given how slowly college characteristics change over time. We are able to link 67 percent of OMSCS applicants and 11 percent of MSCS applicants to colleges in IPEDS. For both programs, we can link 88 percent of U.S. citizen applicants to their colleges.
} 
the online version of the program is large, with well over 10 times more American applicants to OMSCS than to MSCS. Third, eighty percent of those admitted to the online program accept those offers and enroll, suggesting that relatively few such admits find alternative higher education options compelling. Large demand for OMSCS from a mid-career population uninterested in its in-person equivalent and the high enrollment rate among admits both suggest that OMSCS provides an educational pathway for which there has previously been no compelling, competing alternative. To strengthen the case for this argument, we turn to a second empirical strategy that focuses on causal inference and complements the descriptive analysis above.

\section{The Impact of Online Access on Educational Trajectories}

\subsection{Regression Discontinuity Design}

Our goal is to determine whether the existence of an online option alters applicants' educational trajectories. If not for access to such an option, would its applicants pursue other educational options? Or does the online option lack close substitutes in the current higher education market? The difficulty in answering this question is that applicants admitted to OMSCS are generally academically stronger than and differ along other dimensions from those denied admission. Comparing the subsequent educational trajectories of these two groups of students would confound the impact of online access with the impact of underlying academic skills and other characteristics.

We solve this problem by identifying an exogenous source of variation in the probability that an applicant had access to the online option. In particular, though OMSCS admitted a wider range of students in later cohorts, the program decided to somewhat constrain the number of students admitted to the very first cohort in spring 2014. OMSCS did this to ensure that any challenges inherent in starting a new program would not be compounded by an overly large enrollment total. The chief admissions officer therefore read applications in descending order of undergraduate GPA and offered immediate admission only to the first 500 or so applications he read that he deemed admissible. As a result, only applicants with an undergraduate GPA of 3.26 or higher were eligible for admission in spring 2014. 
The admissions officer ultimately read all applications and some students both below and above the 3.26 threshold were made offers of deferred admission. Such students were allowed to enroll in summer 2014, fall 2014 or spring 2015. The admissions data we have can not distinguish between students made offers of admission for spring 2014 and those who were offered deferred admission. We therefore measure enrollment outcomes as of fall 2016, well beyond the point at which all spring 2014 applicants would have had to enroll if admitted or would have had time to apply to and enroll in other institutions if rejected. We focus on the probability that a given student received any admission offer, regardless of its timing.

The GPA threshold thus represents an exogenous source of variation in whether a given student was offered admission to OMSCS. We use the threshold to implement a regression discontinuity design (RD) that compares the educational trajectories of applicants just above and below that threshold. Such students should be nearly identical in terms of academic skills, as measured by GPA, as well as other characteristics. They should differ only in their access to the online option. We estimate the impact of having a GPA above the admissions threshold on enrollment outcomes of the first applicant cohort through the following baseline specification:

$$
\text { Enrolled }_{i}=\beta_{0}+\beta_{1} \text { Admissible }_{i}+\beta_{2} G P A_{i}+\beta_{3} \text { Admissible }_{i} \times G P A_{i}+\epsilon_{i} .
$$

Here, Enrolled indicates enrollment status in OMSCS or other programs for applicant $i$, Admissible indicates the applicant is above the GPA threshold and GPA measures his distance from that threshold in GPA points. In this local linear regression, the two GPA variables model the relationship between GPA and college outcomes as linear, with the interaction term allowing that slope to vary on either side of the threshold. The coefficient on Admissible thus measures the difference in OMSCS enrollment probability between applicants just above and just below that threshold. This specification generates intent-to-treat estimates of the impact of increased access to OMSCS.

Using the same basic specification, we also generate instrumental variables estimates of the impact of admission on enrollment, where admission is instrumented with having an immediately 
admissible GPA. Specifically, we estimate the first stage equation

$$
\text { Admitted }_{i}=\alpha_{0}+\alpha_{1} \text { Admissible }_{i}+\alpha_{2} G P A_{i}+\alpha_{3} \text { Admissible }_{i} \times G P A_{i}+\epsilon_{i} .
$$

where Admitted indicates eventual admission to OMSCS. We then use predicted values of Admitted to estimate a second stage of the form

$$
\text { Enrolled }_{i}=\gamma_{0}+\gamma_{1} \text { Admitted }_{i}+\gamma_{2} G P A_{i}+\gamma_{3} \text { Admissible }_{i} \times G P A_{i}+\epsilon_{i} .
$$

This yields estimates of the impact of OMSCS admission on enrollment choices for compliers at the margin, namely those students for whom the threshold itself altered their probability of eventual admission. We think of this as a matriculation rate for such applicants.

Following Lee and Card (2008), our baseline specifications for all of these estimates cluster standard errors by distance from the GPA threshold because GPA is a fairly discrete variable, with many students reporting values that are multiples of 0.1 or 0.25 . To improve precision, we include demographic controls for gender, race/ethnicity, citizenship, age, employment and college major. Optimal bandwidths, as suggested both by Imbens and Kalyanaraman (2012) and Calonico et al. (2014), are between 0.3 and 0.5 GPA points for all outcomes. We treat 0.5 GPA points as our default bandwidth but show that our results are robust to use of smaller and larger bandwidths, as well as to exclusion of demographic controls.

Validity of our RD estimates requires that students not systematically manipulate which side of the GPA threshold they fall on. Though they do self-report GPAs, two facts suggest little scope for manipulation. First, applicants were required to submit transcripts and thus knew that their self-reported GPAs might be checked against officially reported ones. Second, applicants had no knowledge that a GPA of 3.26 would play any role in the admissions process, a fact that was decided only after all applications had been submitted. The only GPA criterion publicized was that a GPA of 3.0 or higher was preferred, though applicants with lower GPAs could be admitted. It thus seems highly unlikely that there could be differential sorting across the 3.26 threshold. We confirm this in two ways. 
First, as suggested by McCrary (2008), we show in Figure A.1 that the density of students just above the threshold looks similar to the density just below. Multiples of 0.1 , as well as 3.0 and 4.0, are particularly common, but there is no clear difference in the distribution of GPAs around the eligibility threshold. Formal tests show no evidence that GPAs just above 3.26 are over-represented relative to GPAs just below 3.26, suggesting no obvious manipulation by students. Second, we confirm that observable covariates are balanced across the threshold by running the specification in Equation 1 using such covariates as outcomes. Table A.2 shows the results of these covariate balance tests, using a variety of bandwidths. There is no practically or statistically significant evidence of differential sorting across the threshold in terms of gender, race, citizenship, age, employment, or college major. The balance of density and covariates at the threshold suggest that students on either side of the threshold are similar along both observed and unobservable dimensions. Our regression discontinuity coefficients should therefore provide unbiased estimates of the impact of online access on educational trajectories.

\subsection{Causal Estimates}

We first document how the GPA threshold affected the probability of admission to OMSCS. The relationship between GPA and the probability of being offered admission, seen in Panel A of Figure 3. shows a clear discontinuity. The first stage estimates in column 1 of Table 4 suggest that those just above the GPA threshold were about 20 percentage points more likely to be admitted to the online program than their counterparts with slightly lower GPAs. This difference represents the extent to which the GPA threshold generated exogenous variation in access to the online option.

Importantly, access to the online program generates enrollment in that program. We define OMSCS enrollment as a student having enrolled in at least one semester by fall 2016 18 At that point, all immediate and deferred admissions offers would have expired, and applicants would have had the opportunity to apply to and enroll in other, competing degree programs. Panel B of Figure 3 shows the fraction of applicants who ever enrolled in OMSCS. The graphical evidence, as

\footnotetext{
${ }^{18}$ The relationship between spring 2014 enrollment and GPA in Figure A.2 is consistent with the requirement of a GPA of at least 3.26 for immediate admission. Only four applicants below the GPA threshold appear to have enrolled in OMSCS in spring 2014.
} 
well as the estimates in column 2 of Table 4, suggest that threshold-based admissibility increases enrollment in the online option by slightly more than 20 percentage points. This implies that roughly all of the marginal applicants admitted because of the GPA threshold accepted the offer of admission and enrolled. Instrumental variables estimates, shown in column 3, confirm that the matriculation rate of such students is close in magnitude and statistically indistinguishable from 100 percent. These applicants appear not to have competing options that would cause them to decline their admissions offer.

Importantly, though admission affects enrollment, admission timing does not appear to. Figure A.3 shows OMSCS enrollment rates as a function of GPA, for the sub-sample of applicants offered admission. Those above the threshold were largely given immediate offers and those below deferred offers, yet at the threshold there is no clear difference in the probability of enrolling in OMSCS, conditional on admission. The point estimate of the discontinuity is close to zero and statistically insignificant whether we use our default bandwidth of 0.5 or the Imbens-Kalyanaraman optimal bandwith of 0.3 .

Examination of enrollment in other programs confirms that OMSCS has no close substitutes. Panel A of Figure 4 shows the fraction of OMSCS applicants who enrolled in other, non-OMSCS programs by fall 2016. The overall levels of such enrollment are quite low, with fewer than 20 percent of those just below the threshold enrolling elsewhere. The few alternatives chosen by such applicants are rarely the more prestigious competitors of MSCS, such as Carnegie Mellon or University of Southern California, but are instead lower-ranked online programs from institutions such as DeVry University or Arizona State University. This is in contrast to MSCS applicants, many hundreds of whom choose those prestigious competitors over Georgia Tech. Panel B shows that over 50 percent of MSCS applicants enroll in alternative U.S. programs, a fraction that rises to 65 percent when considering just U.S. applicants to the in-person program. Those interested in the online program appear to have fewer competing alternatives than those interested in the in-person program.

In addition to the low overall rate of online program applicants enrolling in alternatives to OMSCS, there is also no visually apparent discontinuity in non-OMSCS enrollment, with columns 
4 and 5 of Table 4 showing statistically insignificant point estimates close to zero. If access to OMSCS were substituting for other in-person programs, we would expect to see a clear drop in enrollment elsewhere to the right of the GPA threshold. Though our regression discontinuity estimates are generated by those at a particular point in the GPA distribution, it is worth noting that those with much higher or lower GPAs also do not appear to enroll in non-OMSCS options. This suggests the market is not providing appealing alternatives for a wide range of students for whom OMSCS is appealing. In contrast, most MSCS applicants with lower and higher GPAs find suitable alternatives in which to enroll.

Access to the online option therefore increases the number of people pursuing education at all. We see this in Figure 5, which shows the fraction of applicants enrolling in any formal higher education. There is a large, clear discontinuity at the admissions threshold, with estimates from column 6 of Table 4 suggesting that admissibility to the online program increases enrollment in formal higher education by about 20 percentage points. The instrumental variables estimates in column 7 imply that roughly 100 percent of the marginal admits to OMSCS represent new entrants into formal higher education. Access to this online option thus increases the number of people pursuing education.

We perform a number of robustness checks to confirm that our estimates are not sensitive to our specification choices. The first two rows of Table 4 show that inclusion of demographic controls improves the precision of our estimates, but does not meaningfully alter their magnitude. The remaining rows of the table show that our point estimates are robust to a fairly wide set of bandwidths, including those close to the optimal bandwidths mentioned previously. To check that our estimated discontinuities in admission, OMSCS enrollment and overall enrollment are not driven by spurious features of the data, we test for placebo discontinuities by running our baseline regression specification placing the admissions threshold at GPA values other than 3.26. The resulting coefficients are shown in panel A of Figures A.4. A.5 and A.6. In all cases, the actual threshold of 3.26 generates the largest discontinuity and the only one that is positive and statistically significant.

One other potential concern is that the location of the threshold was endogenous to the qual- 
ity of the applicant pool in that part of the GPA distribution. If students with a 3.26 GPA were of particularly high quality and thus ended the admissions process by using up the program's final capacity, then our estimates might be biased by correlations between such quality and enrollment decisions. To test whether such endogenous threshold location is generating bias, panel B of Figures A.4 A.5 and A.6 show estimated discontinuities from donut hole RD specifications that exclude observations close to the threshold. The resulting coefficients are, if anything, slightly larger, suggesting that our estimates are not driven by observations very close to the threshold.

As a final check, we explore heterogeneity in enrollment impacts of online access in Table 5. Limiting the sample to non-AT\&T employees has little effect on our point estimates, suggesting that our results are not driven by this potentially unusual subset of applicants. Limiting the sample to U.S. citizens has similarly little effect. Subsequent rows separate the sample by age, gender and race. The main takeaway from these estimates is that there is no subgroup of applicants for whom access to OMSCS substitutes for enrollment in other educational programs. None of the point estimates in columns 4 and 5 are significantly negative. The result is that, for all subgroups for whom the threshold clearly generates variation in access to OMSCS, such access clearly increases overall enrollment in higher education.

\section{Discussion and Conclusion}

Our descriptive evidence shows large demand for the first low-cost online degree offered by a highly-ranked institution. Applicant pools to the online and in-person versions of this degree program show almost no overlap in individuals or in demographic characteristics. Unlike its inperson equivalent, the online option generates demand largely from mid-career Americans. Large demand from older, employed individuals is consistent with the possibility that the geographic and temporal flexibility of the online option are critical to its appeal. Online education can provide mid-career training without forcing individuals to quit their jobs or move to locations with appropriate educational institutions. Relatively low demand for the online option from non-Americans is consistent with the value of in-person programs stemming at least partially from physical access to U.S. social networks and labor markets. 
Our causal evidence shows that this online option expands access to formal education and does not substitute for other programs. Eighty percent of those accepted by OMSCS enroll. The vast majority of applicants denied access do not pursue any form of further formal education. Most importantly, gaining access to the online option does not decrease the extent to which students enroll in other educational programs. This is the first rigorous evidence that we know of showing an online degree program can increase educational attainment, implying that the higher education market had previously been failing to meet demand for this particular bundle of program characteristics.

This model of online education thus has the potential to substantially increase the national stock of computer science human capital. OMSCS enrolls about 1,170 Americans annually. Though it is too early to measure completion rates, NSC data on the 2014 OMSCS enrollees suggest that at least 62 percent are still enrolled at least two years after they begin the program and thus apparently on track to graduate. The actual fraction who will graduate may be substantially higher than that, given that the flexible nature of the program and mid-career students' busy professional and family lives makes persistence somewhat difficult to measure. For example, over 25 percent of students who take a fall or spring semester off appear to re-enroll in the subsequent spring or fall semester. Persistence to graduation could therefore be as high as 90 percent ${ }^{19}$ Conservatively, if only 62 percent of enrollees graduate, OMSCS will annually produce about 725 American computer science master's degree recipients. According to IPEDS' Completion Survey, about 11,000 American citizens earned a master's degree in computer science in 2013, the most recent year data is available. This implies that OMSCS will generate a seven percent increase in the national production of such degrees. If 90 percent of enrollees graduate, OMSCS will increase such production by 10 percent. Either way, the program will produce a substantial fraction of such computer science human capital.

We conclude with two questions raised by this research. The first concerns external validity. To what extent will the conclusions drawn from this particular online program apply to other populations and subjects? It seems likely, for example, that mid-career training in other fields

\footnotetext{
${ }^{19}$ By comparison, about 95 percent of MSCS students graduate within two years.
} 
might be amenable to this model. The recent rise of "iMBA" and "micro-master's" programs suggests that other institutions believe there are untapped markets in such training. Whether such low-cost, high-quality models can make inroads in undergraduate or secondary education remains to be seen.

The second question concerns the quality of the education that this online option provides. How large are the learning and labor market impacts of this online degree and how do they compare to that of the in-person equivalent? Comparing the undergraduate colleges attended by OMSCS and MSCS students suggests that OMSCS students are, on average, somewhat weaker academically than their in-person counterparts. Nonetheless, comparisons of student achievement across the online and in-person formats suggests that OMSCS students finish their courses with at least as much knowledge as their in-person counterparts (Goel and Joyner, 2016). We hope to explore in subsequent work the extent to which the OMSCS degree is valued by the labor market and whether and how it affects career advancement. Whether the labor market perceives OMSCS graduates as similar in quality to their in-person counterparts will have implications for the impact of such models on the postsecondary sector more generally (Hoxby, 2014). 


\section{References}

Alpert, W. T., K. A. Couch, and O. R. Harmon (2016). A randomized assessment of online learning. American Economic Review 106(5), 378-82.

Banerjee, A. V. and E. Duflo (2014). (Dis) organization and success in an economics MOOC. The American Economic Review 104(5), 514-518.

Bettinger, E., L. Fox, S. Loeb, and E. Taylor (2015). Changing distributions: How online college classes alter student and professor performance. Technical report, Working Paper, Stanford University.

Bowen, W. G., M. M. Chingos, K. A. Lack, and T. I. Nygren (2014). Interactive learning online at public universities: Evidence from a six-campus randomized trial. Journal of Policy Analysis and Management 33(1), 94-111.

Calonico, S., M. D. Cattaneo, and R. Titiunik (2014). Robust nonparametric confidence intervals for regression-discontinuity designs. Econometrica 82(6), 2295-2326.

Deming, D. J., C. Goldin, L. F. Katz, and N. Yuchtman (2015). Can online learning bend the higher education cost curve? The American Economic Review 105(5), 496-501.

Deming, D. J., N. Yuchtman, A. Abulafi, C. Goldin, and L. F. Katz (2016). The value of postsecondary credentials in the labor market: An experimental study. The American Economic Review 106(3), 778-806.

Dynarski, S. M., S. W. Hemelt, and J. M. Hyman (2015). The missing manual: Using National Student Clearinghouse data to track postsecondary outcomes. Educational Evaluation and Policy Analysis 37(1 suppl), 53S-79S.

Figlio, D., M. Rush, and L. Yin (2013). Is it live or is it internet? Experimental estimates of the effects of online instruction on student learning. Journal of Labor Economics 31(4), 763-784.

Goel, A. and D. Joyner (2016). An experiment in teaching cognitive systems online. International Journal for Scholarship of Technology Enhanced Learning 1(1).

Hoxby, C. M. (2014). The economics of online postsecondary education: MOOCs, nonselective education, and highly selective education. The American Economic Review 104(5), 528-533.

Imbens, G. and K. Kalyanaraman (2012). Optimal bandwidth choice for the regression discontinuity estimator. The Review of economic studies 79(3), 933-959.

Joyce, T., S. Crockett, D. A. Jaeger, O. Altindag, and S. D. O'Connell (2015). Does classroom time matter? Economics of Education Review 46, 64-77.

Krieg, J. M. and S. E. Henson (2016). The educational impact of online learning: How do university students perform in subsequent courses? Education Finance and Policy 11(4), 426-448.

Lee, D. S. and D. Card (2008). Regression discontinuity inference with specification error. Journal of Econometrics 142(2), 655-674. 
McCrary, J. (2008). Manipulation of the running variable in the regression discontinuity design: A density test. Journal of Econometrics 142(2), 698-714.

McPherson, M. S. and L. S. Bacow (2015). Online higher education: Beyond the hype cycle. The Journal of Economic Perspectives 29(4), 135-153.

Perna, L., A. Ruby, R. Boruch, N. Wang, J. Scull, C. Evans, and S. Ahmad (2013). The life cycle of a million mooc users. In MOOC Research Initiative Conference, pp. 5-6.

Xu, D. and S. S. Jaggars (2014). Performance gaps between online and face-to-face courses: Differences across types of students and academic subject areas. The Journal of Higher Education 85(5), 633-659. 
Figure 1: Citizenship of In-Person and Online Program Applicants

(A) In-Person Program Applicants

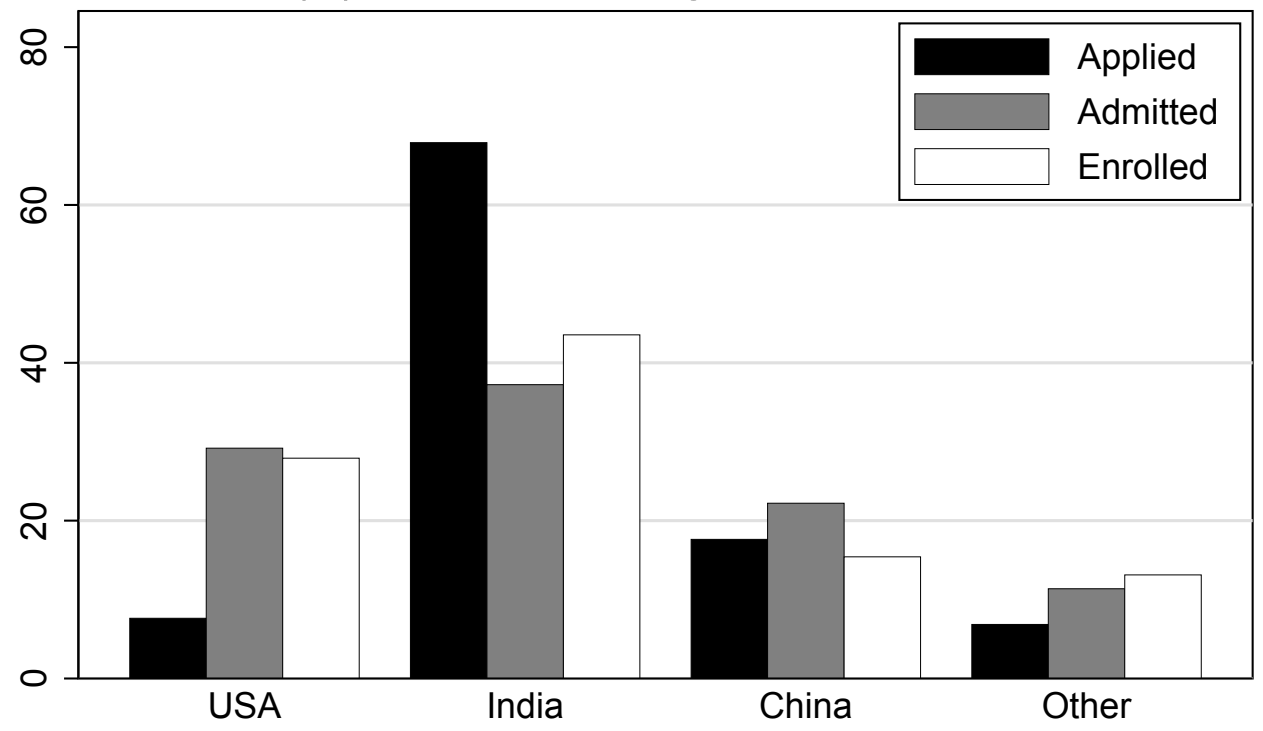

(B) Online Program Applicants

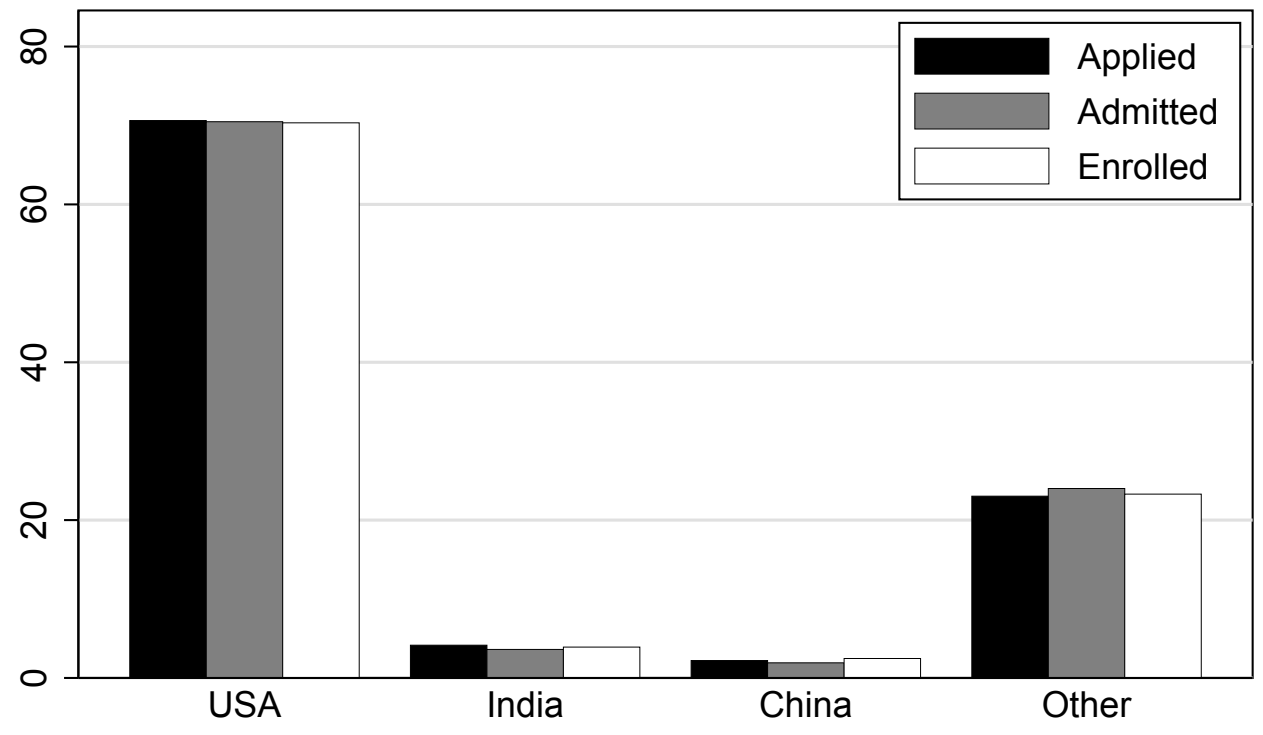

Notes: Panels A and B show the distribution of citizenship of applicants to the in-person and online programs respectively. Panel A includes all 2013-16 in-person program applicants. Panel B includes all 2014-16 online program applicants. From left to right, the three bars show the fraction of applicants, admitted students, and enrolled students from each country. 
Figure 2: Age Distribution of In-Person and Online Program Applicants

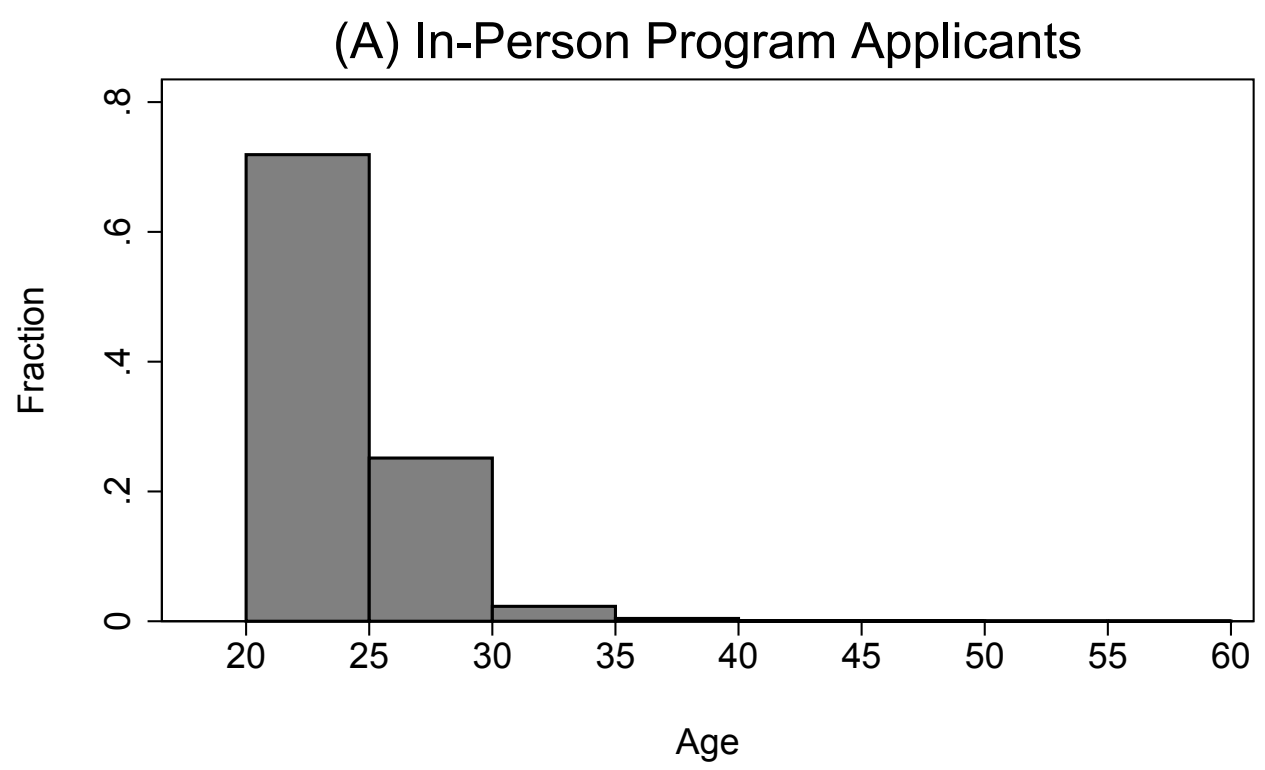

(B) Online Program Applicants

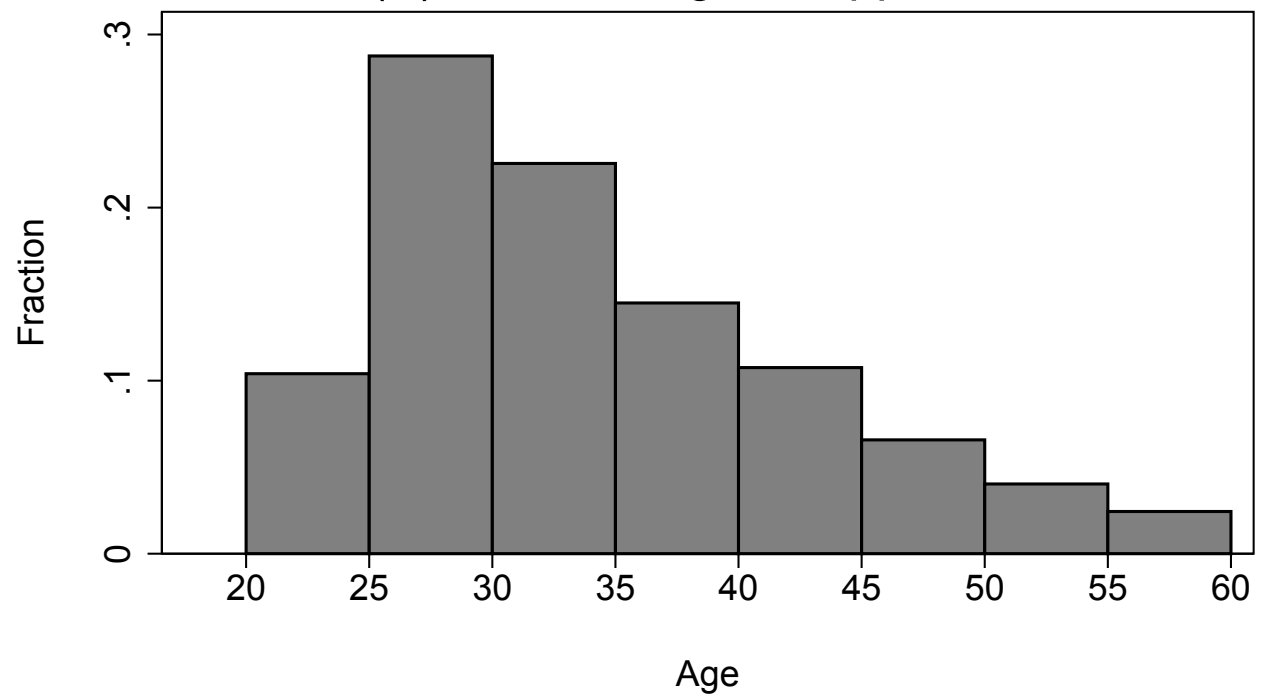

Notes: Panels A and B show the age distribution of applicants to the in-person and online programs respectively. Panel A includes all 2013-16 in-person program applicants. Panel B includes all 2014-16 online program applicants. The 75 applicants with ages below twenty or above sixty are rounded to those values for this figure. 
Figure 3: Access to and Enrollment in the Online Program

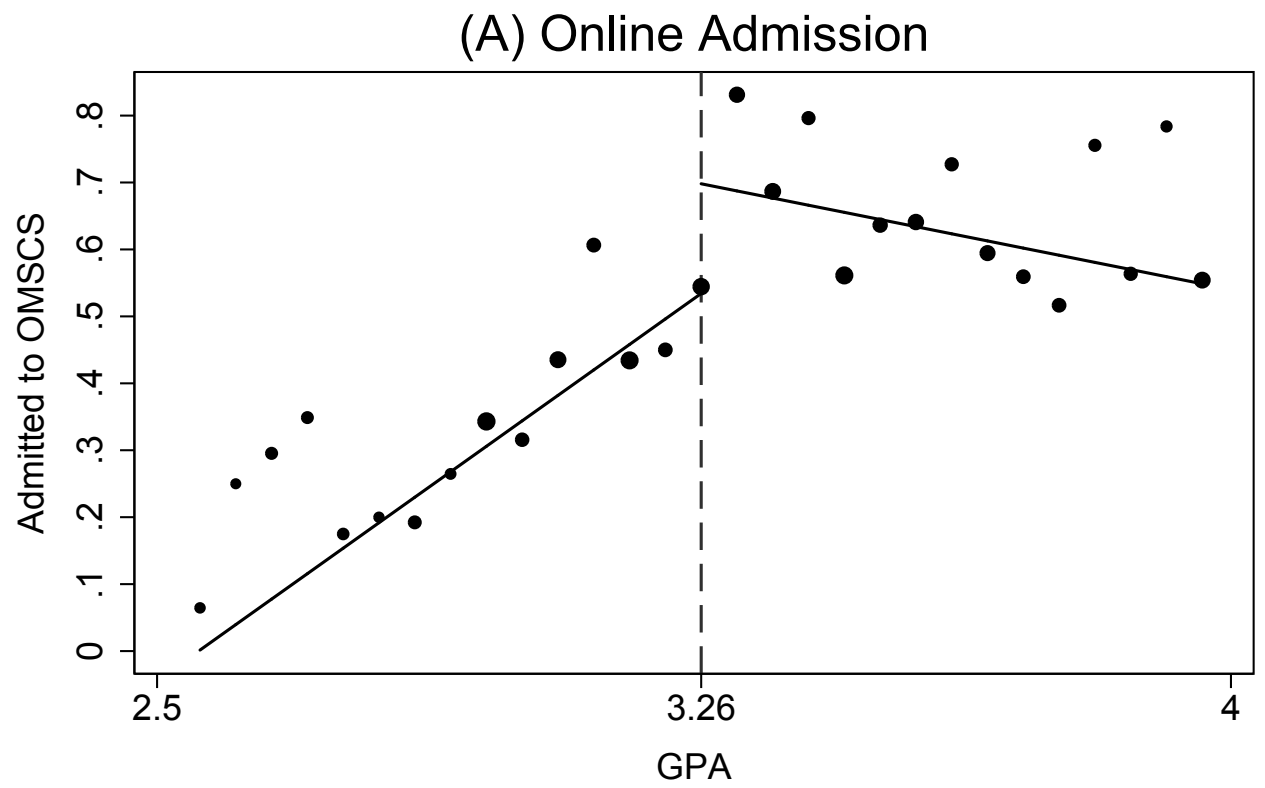

(B) Online Enrollment

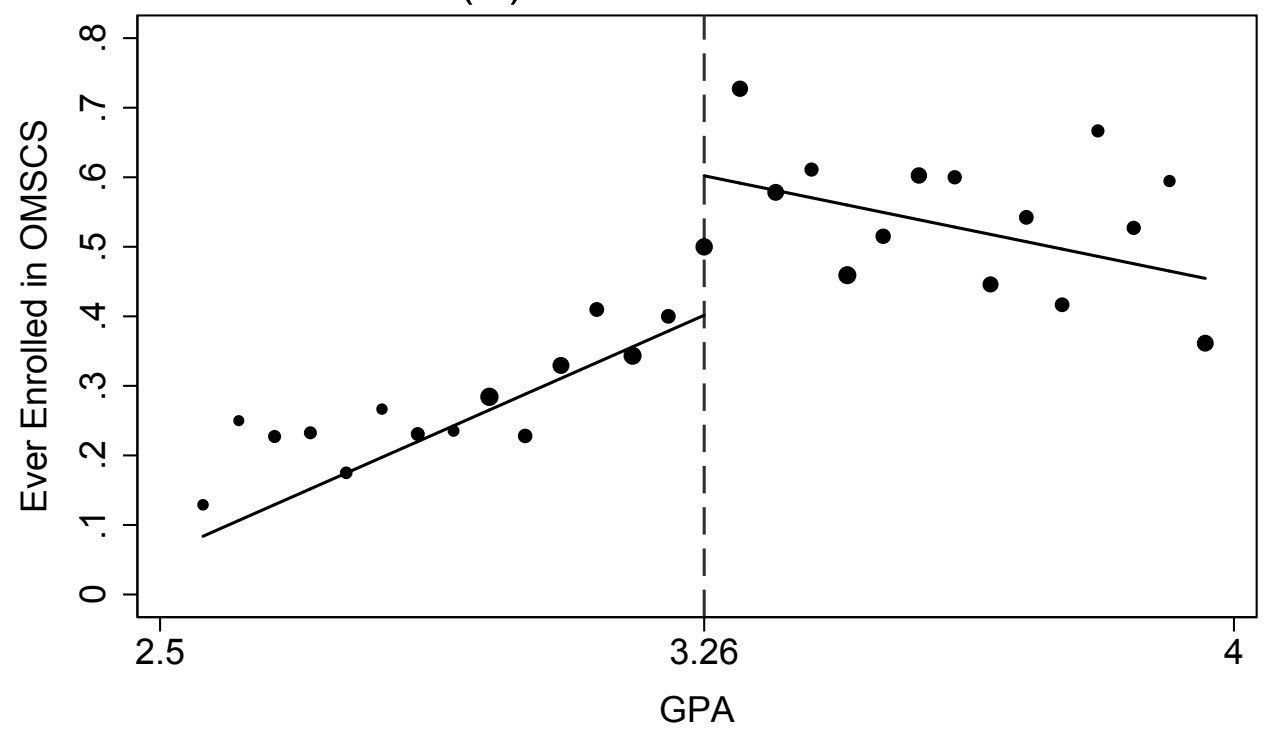

Notes: The above figure shows as a function of college GPA the fraction of spring 2014 online program applicants who were admitted (panel A) and who enrolled in the online program by fall 2016 (panel B). The sample is limited to those with GPAs between 2.5 and 4.0. The dots shown come from binning the data in intervals of 0.05 from the threshold, with dot size proportional to the number of applicants in each bin. Also shown are fitted lines from a local linear regression discontinuity model using a bandwidth of 0.5 . 
Figure 4: Enrollment in Other Programs
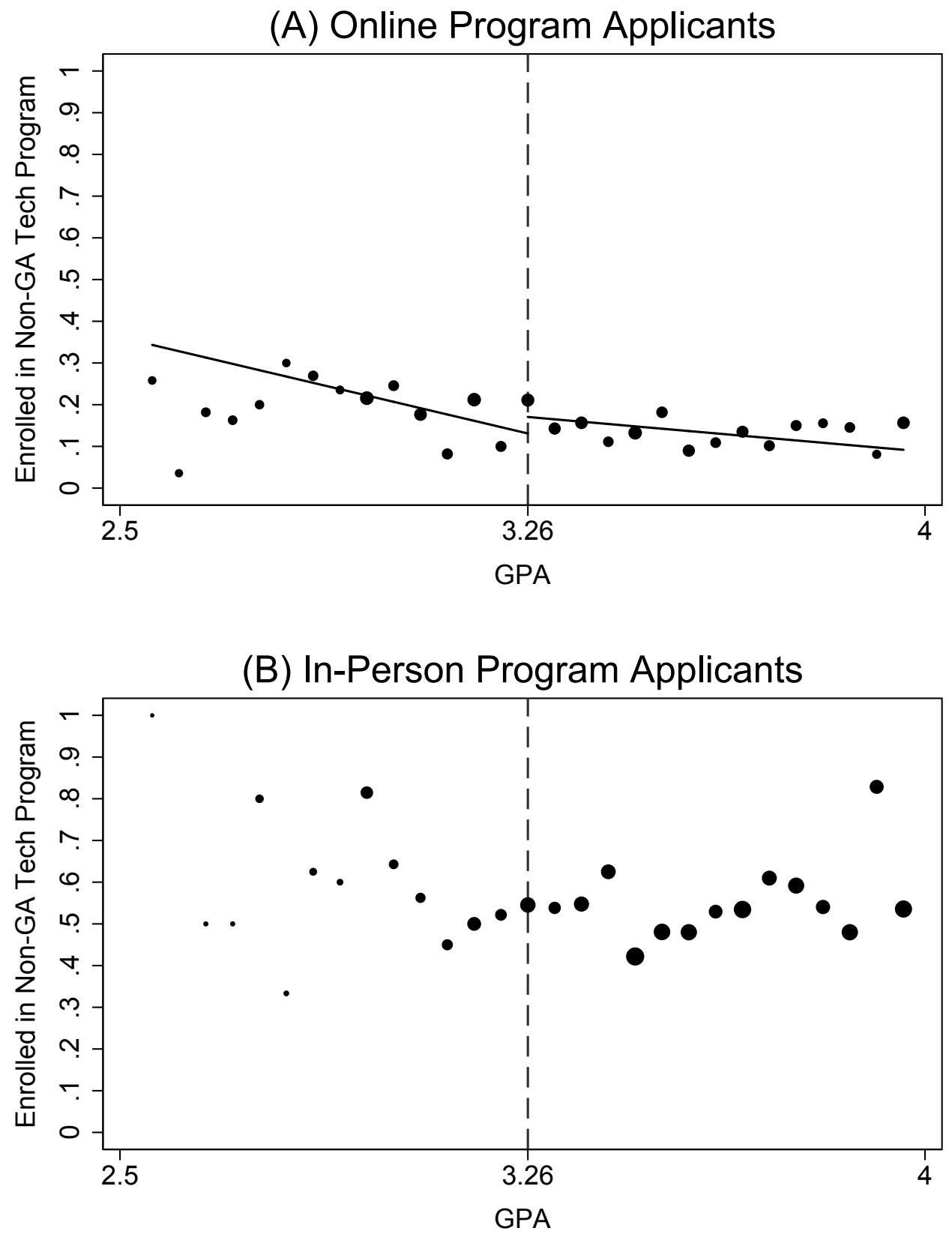

Notes: The above figure shows as a function of college GPA the fraction of spring 2014 online program applicants (panel A) and fall 2013 and 2014 in-person program applicants (panel B) who by fall 2016 had enrolled in any non-Georgia Tech program. The sample is limited to those with GPAs between 2.5 and 4.0. The dots shown come from binning the data in intervals of 0.05 from the threshold, with dot size proportional to the number of applicants in each bin. Also shown in panel A are fitted lines from a local linear regression discontinuity model using a bandwidth of 0.5 . 
Figure 5: Enrollment in Any Degree Program

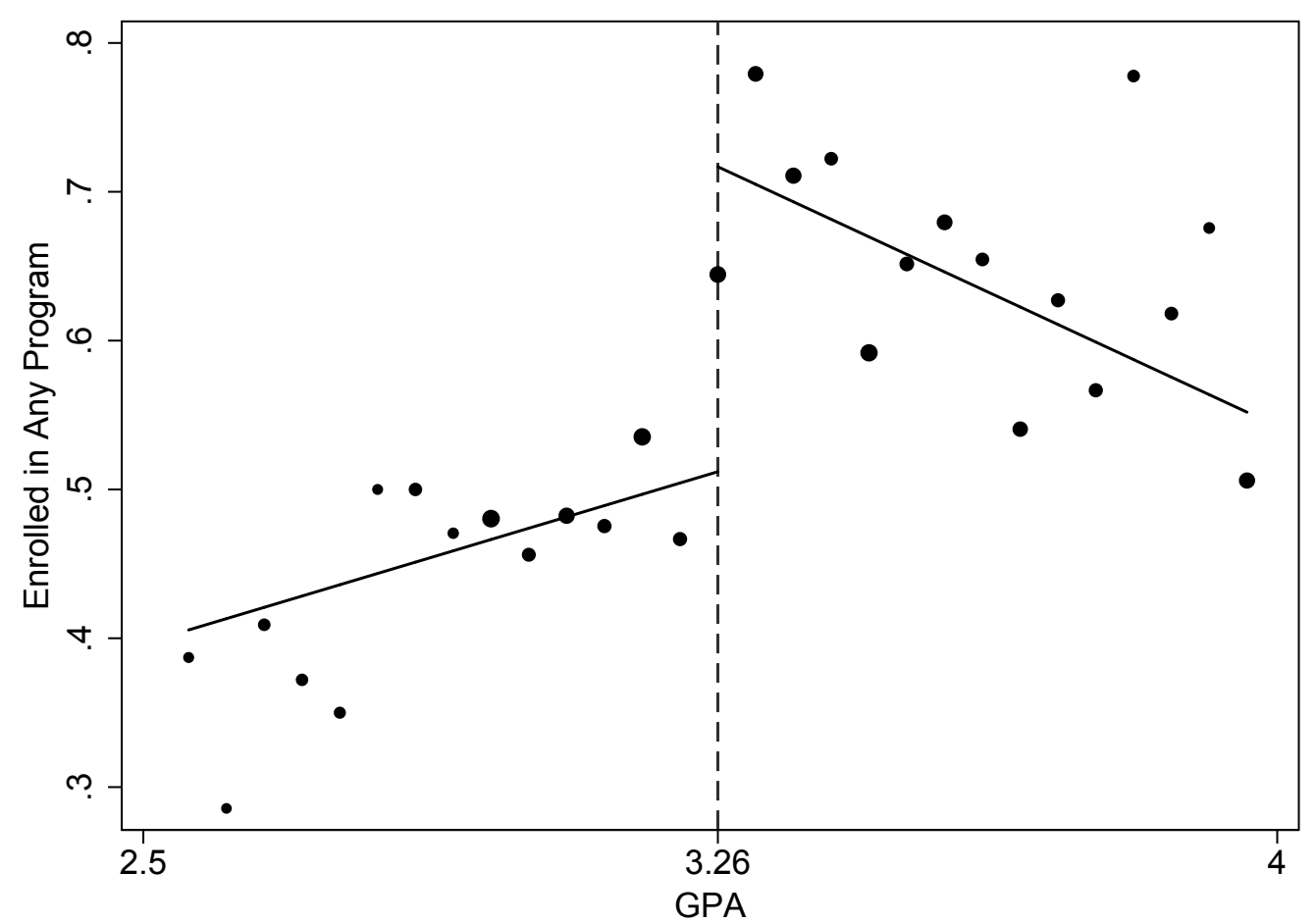

Notes: The above figure shows as a function of college GPA the fraction of spring 2014 online program applicants who by fall 2016 had enrolled in any program, OMSCS or otherwise. The sample is limited to those with GPAs between 2.5 and 4.0. The dots shown come from binning the data in intervals of 0.05 from the threshold, with dot size proportional to the number of applicants in each bin. Also shown are fitted lines from a local linear regression discontinuity model using a bandwidth of 0.5 . 
Table 1: Characteristics of Program Applicants and Enrollees

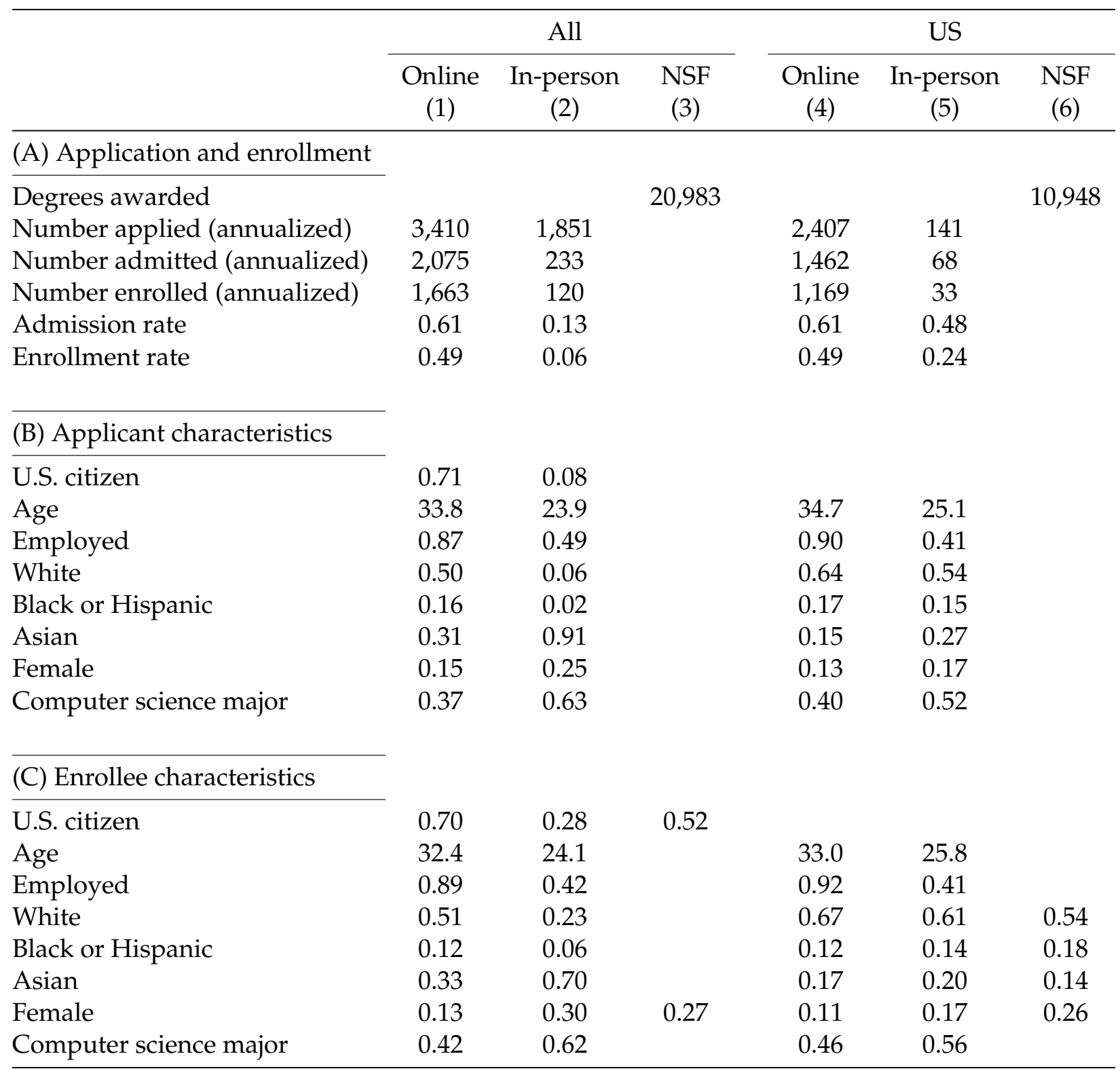

Notes: Data in columns 1 and 4 come from all 2014-16 online program applicants. Data in columns 2 and and 5 come from all 2013-16 in-person program applicants. Column 3 describes those who completed computer science master's degrees in the US in 2013 and comes from 2013 IPEDS Completion Survey, accessed through the NSF's WebCASPAR site. Columns 1-3 include all individuals, while columns 4-6 limit the sample to American citizens. For comparability, the numbers in columns 1,2, 4 and 5 of panel A are scaled to be annual. In panel A, the enrollment rate is calculated as the fraction of applicants who enrolled. 
Table 2: Distribution of Employers for Online Program Applicants

\begin{tabular}{|c|c|c|c|}
\hline $\begin{array}{l}\text { Listed } \\
\text { employer }\end{array}$ & $\begin{array}{l}\text { Number of } \\
\text { applicants }\end{array}$ & $\begin{array}{c}\text { Percentage } \\
\text { of total }\end{array}$ & $\begin{array}{c}\text { Cumulative } \\
\text { percentage }\end{array}$ \\
\hline AT\&T & 1,062 & 10.44 & 10.44 \\
\hline Microsoft & 105 & 1.03 & 11.47 \\
\hline Intel & 99 & 0.97 & 12.44 \\
\hline IBM & 94 & 0.92 & 13.36 \\
\hline U.S. Air Force & 90 & 0.88 & 14.24 \\
\hline Google & 78 & 0.77 & 15.01 \\
\hline U.S. Army & 68 & 0.67 & 15.68 \\
\hline United Parcel Service & 66 & 0.65 & 16.33 \\
\hline Lockheed Martin & 63 & 0.62 & 16.95 \\
\hline Amazon & 59 & 0.58 & 17.53 \\
\hline Cisco Systems & 58 & 0.57 & 18.1 \\
\hline Oracle & 56 & 0.55 & 18.65 \\
\hline General Motors & 51 & 0.50 & 19.15 \\
\hline Boeing & 47 & 0.46 & 19.61 \\
\hline General Electric & 47 & 0.46 & 20.07 \\
\hline Raytheon & 46 & 0.45 & 20.52 \\
\hline Northrop Grumman & 43 & 0.42 & 20.94 \\
\hline Hewlett-Packard & 40 & 0.39 & 21.33 \\
\hline Accenture & 39 & 0.38 & 21.71 \\
\hline Apple & 33 & 0.32 & 22.03 \\
\hline Bank of America & 31 & 0.30 & 22.33 \\
\hline J.P. Morgan Chase & 29 & 0.29 & 22.62 \\
\hline U.S. Navy & 28 & 0.28 & 22.90 \\
\hline Booz Allen Hamilton & 26 & 0.26 & 23.16 \\
\hline Capital One & 26 & 0.26 & 23.42 \\
\hline Employers with 2-25 applicants & 1,930 & 18.97 & 42.39 \\
\hline Employers with 1 applicant & 4,473 & 43.97 & 86.36 \\
\hline No employer listed & 1,385 & 13.62 & 100 \\
\hline
\end{tabular}

Notes: Shown above are the top 25 employers listed by all 2014-16 online program applicants, as well as the total number of applicants from employers with 2-25 applicants, from employers with only one applicant, and with no employer listed. 
Table 3: Applicants' Undergraduate College Characteristics

\begin{tabular}{lcccccc}
\hline & \multicolumn{2}{c}{ Applicants } & \multicolumn{2}{c}{ Admits } & \multicolumn{2}{c}{ Enrollees } \\
& Online & In-person & Online & In-person & Online & In-person \\
\hline SAT math score & 649 & 679 & 655 & 692 & 657 & 692 \\
Fraction low income & 0.23 & 0.20 & 0.22 & 0.17 & 0.22 & 0.17 \\
Six-year graduation rate & 0.61 & 0.70 & 0.62 & 0.73 & 0.63 & 0.71 \\
N & 6,882 & 800 & 4,316 & 341 & 3,449 & 170 \\
\hline
\end{tabular}

Notes: Shown above are the means of undergraduate college characteristics for all online and in-person program applicants, admits, and enrollees, as derived from the 2005 wave of IPEDS. All differences between the two programs are statistically significant at the one percent level. The sample includes only students whose listed undergraduate colleges were found in IPEDS. SAT math scores are the 75th percentile of the incoming freshman distribution. The fraction of students classified as low income is measured by the proportion receiving federal grant aid. 
Table 4: Access to OMSCS and Enrollment in Higher Education

\begin{tabular}{|c|c|c|c|c|c|c|c|}
\hline & Admitted & Enrollec & OMSCS & Enrolle & lsewhere & Enrolled & nywhere \\
\hline & (FS) & $(\mathrm{RF})$ & (IV) & (RF) & (IV) & (RF) & (IV) \\
\hline & $(1)$ & $(2)$ & $(3)$ & $(4)$ & (5) & $(6)$ & $(7)$ \\
\hline (A) $\mathrm{BW}=0.7$ & & & & & & & \\
\hline Admissible & $\begin{array}{c}0.178^{* * *} \\
(0.062)\end{array}$ & $\begin{array}{c}0.197^{* * *} \\
(0.050)\end{array}$ & $\begin{array}{c}1.109^{* * *} \\
(0.216)\end{array}$ & $\begin{array}{l}-0.004 \\
(0.036)\end{array}$ & $\begin{array}{l}-0.022 \\
(0.197)\end{array}$ & $\begin{array}{c}0.169^{* * *} \\
(0.039)\end{array}$ & $\begin{array}{c}0.953^{* * *} \\
(0.290)\end{array}$ \\
\hline (B) $\mathrm{BW}=0.7$, controls & & & & & & & \\
\hline Admissible & $\begin{array}{c}0.189^{* * *} \\
(0.052)\end{array}$ & $\begin{array}{c}0.205^{* * *} \\
(0.040)\end{array}$ & $\begin{array}{c}1.081^{* * *} \\
(0.190)\end{array}$ & $\begin{array}{l}-0.007 \\
(0.034)\end{array}$ & $\begin{array}{l}-0.038 \\
(0.173)\end{array}$ & $\begin{array}{c}0.173^{* * *} \\
(0.036)\end{array}$ & $\begin{array}{c}0.915^{* * *} \\
(0.249)\end{array}$ \\
\hline (C) $\mathrm{BW}=0.5$, controls & & & & & & & \\
\hline Admissible & $\begin{array}{c}0.187^{* * *} \\
(0.066)\end{array}$ & $\begin{array}{c}0.217^{* * *} \\
(0.048)\end{array}$ & $\begin{array}{c}1.159^{* * *} \\
(0.261)\end{array}$ & $\begin{array}{c}0.032 \\
(0.043)\end{array}$ & $\begin{array}{c}0.172 \\
(0.265)\end{array}$ & $\begin{array}{c}0.212^{* * *} \\
(0.043)\end{array}$ & $\begin{array}{c}1.137^{* * *} \\
(0.386)\end{array}$ \\
\hline (D) $\mathrm{BW}=0.3$, controls & & & & & & & \\
\hline Admissible & $\begin{array}{c}0.218^{* * *} \\
(0.081)\end{array}$ & $\begin{array}{c}0.234^{* * *} \\
(0.066)\end{array}$ & $\begin{array}{c}1.072^{* * *} \\
(0.237)\end{array}$ & $\begin{array}{c}0.051 \\
(0.054)\end{array}$ & $\begin{array}{c}0.235 \\
(0.306)\end{array}$ & $\begin{array}{c}0.226^{* * *} \\
(0.055)\end{array}$ & $\begin{array}{c}1.037^{* * *} \\
(0.373)\end{array}$ \\
\hline Control mean & 0.41 & 0.36 & & 0.18 & & 0.51 & \\
\hline
\end{tabular}

Notes: Heteroskedasticity-robust standard errors clustered by GPA are in parentheses $\left.{ }^{*} \mathrm{p}<.10^{* *} \mathrm{p}<.05{ }^{* *} \mathrm{p}<.01\right)$. Each regression discontinuity estimate in columns 1, 2, 4 and 6 comes from a local linear model that regresses an indicator for an admission or enrollment outcome on an indicator for being above the GPA threshold of 3.26, distance from that threshold, and the interaction of the two. Columns 3, 5 and 7 contain instrumental variables estimates of the impact of admission on enrollment, where admission has been instrumented with being above the threshold. The sample includes all spring 2014 applicants to OMSCS whose GPA is within the listed bandwidth. The top row includes no controls, while the remaining rows control for gender, race/ethnicity, citizenship, age, employment and college major. Enrollment is measured by fall 2016. The sample size in panels A and B is 1,706, in panel $C$ is 1,365, in panel D is 926 and in panel E ranges from 1,051 to 1,293. Listed below each column is the mean of the outcome for those 0.01-0.10 GPA points below the threshold. 
Table 5: Heterogeneity in Enrollment Impacts of Access to Online Option

\begin{tabular}{|c|c|c|c|c|c|c|c|}
\hline & \multirow{3}{*}{$\begin{array}{l}\text { Admitted } \\
\text { (FS) } \\
(1)\end{array}$} & \multicolumn{2}{|c|}{ Enrolled OMSCS } & \multicolumn{2}{|c|}{ Enrolled elsewhere } & \multicolumn{2}{|c|}{ Enrolled anywhere } \\
\hline & & $(\mathrm{RF})$ & (IV) & $(\mathrm{RF})$ & (IV) & $(\mathrm{RF})$ & (IV) \\
\hline & & & (3) & & & & $(7)$ \\
\hline Excluding AT\&T & $\begin{array}{c}0.225^{* * *} \\
(0.078)\end{array}$ & $\begin{array}{c}0.265^{* * *} \\
(0.058)\end{array}$ & $\begin{array}{c}1.178^{* * *} \\
(0.248)\end{array}$ & $\begin{array}{c}0.036 \\
(0.052)\end{array}$ & $\begin{array}{c}0.158 \\
(0.263)\end{array}$ & $\begin{array}{c}0.260^{* * *} \\
(0.051)\end{array}$ & $\begin{array}{c}1.154^{* * *} \\
(0.372)\end{array}$ \\
\hline $\mathrm{N}$ & 1,062 & 1,062 & 1,062 & 1,062 & 1,062 & 1,062 & 1,062 \\
\hline U.S. citizen & $\begin{array}{l}0.157^{* *} \\
(0.071)\end{array}$ & $\begin{array}{c}0.217^{* * *} \\
(0.054)\end{array}$ & $\begin{array}{c}1.381^{* * *} \\
(0.416)\end{array}$ & $\begin{array}{c}0.009 \\
(0.049)\end{array}$ & $\begin{array}{c}0.055 \\
(0.327)\end{array}$ & $\begin{array}{c}0.204^{* * *} \\
(0.050)\end{array}$ & $\begin{array}{l}1.299^{* *} \\
(0.560)\end{array}$ \\
\hline $\mathrm{N}$ & 1,193 & 1,193 & 1,193 & 1,193 & 1,193 & 1,193 & 1,193 \\
\hline Age $\geq 35$ & $\begin{array}{c}0.309^{* * *} \\
(0.070)\end{array}$ & $\begin{array}{c}0.300^{* * *} \\
(0.069)\end{array}$ & $\begin{array}{c}0.970^{* * *} \\
(0.125)\end{array}$ & $\begin{array}{l}-0.050 \\
(0.064)\end{array}$ & $\begin{array}{l}-0.161 \\
(0.200)\end{array}$ & $\begin{array}{c}0.221^{* * *} \\
(0.070)\end{array}$ & $\begin{array}{c}0.716^{* * *} \\
(0.200)\end{array}$ \\
\hline $\mathrm{N}$ & 668 & 668 & 668 & 668 & 668 & 668 & 668 \\
\hline Age $<35$ & $\begin{array}{c}0.082 \\
(0.088)\end{array}$ & $\begin{array}{l}0.154^{* *} \\
(0.072)\end{array}$ & $\begin{array}{c}1.866 \\
(1.501)\end{array}$ & $\begin{array}{c}0.109^{* *} \\
(0.051)\end{array}$ & $\begin{array}{c}1.323 \\
(1.807)\end{array}$ & $\begin{array}{c}0.213^{* * *} \\
(0.069)\end{array}$ & $\begin{array}{c}2.580 \\
(2.530)\end{array}$ \\
\hline $\mathrm{N}$ & 697 & 697 & 697 & 697 & 697 & 697 & 697 \\
\hline Male & $\begin{array}{c}0.161^{* *} \\
(0.071)\end{array}$ & $\begin{array}{c}0.216^{* * *} \\
(0.051)\end{array}$ & $\begin{array}{c}1.340^{* * *} \\
(0.399)\end{array}$ & $\begin{array}{c}0.010 \\
(0.053)\end{array}$ & $\begin{array}{c}0.065 \\
(0.346)\end{array}$ & $\begin{array}{c}0.195^{* * *} \\
(0.051)\end{array}$ & $\begin{array}{l}1.212^{* *} \\
(0.554)\end{array}$ \\
\hline $\mathrm{N}$ & 1,184 & 1,184 & 1,184 & 1,184 & 1,184 & 1,184 & 1,184 \\
\hline Female & $\begin{array}{l}0.362^{* *} \\
(0.140)\end{array}$ & $\begin{array}{c}0.206 \\
(0.130)\end{array}$ & $\begin{array}{l}0.570^{* *} \\
(0.252)\end{array}$ & $\begin{array}{l}0.197^{*} \\
(0.112)\end{array}$ & $\begin{array}{c}0.545 \\
(0.416)\end{array}$ & $\begin{array}{c}0.347^{* *} \\
(0.139)\end{array}$ & $\begin{array}{l}0.959^{* *} \\
(0.386)\end{array}$ \\
\hline $\mathrm{N}$ & 181 & 181 & 181 & 181 & 181 & 181 & 181 \\
\hline White or Asian & $\begin{array}{c}0.218^{* * *} \\
(0.069)\end{array}$ & $\begin{array}{c}0.256^{* * *} \\
(0.053)\end{array}$ & $\begin{array}{c}1.172^{* * *} \\
(0.221)\end{array}$ & $\begin{array}{c}0.018 \\
(0.048)\end{array}$ & $\begin{array}{c}0.081 \\
(0.234)\end{array}$ & $\begin{array}{c}0.247^{* * *} \\
(0.048)\end{array}$ & $\begin{array}{c}1.130^{* * *} \\
(0.331)\end{array}$ \\
\hline $\mathrm{N}$ & 1,067 & 1,067 & 1,067 & 1,067 & 1,067 & 1,067 & 1,067 \\
\hline Black or Hispanic & $\begin{array}{c}0.040 \\
(0.114)\end{array}$ & $\begin{array}{c}0.000 \\
(0.115)\end{array}$ & $\begin{array}{c}0.007 \\
(2.845)\end{array}$ & $\begin{array}{c}0.202^{* *} \\
(0.100)\end{array}$ & $\begin{array}{c}4.998 \\
(14.541)\end{array}$ & $\begin{array}{c}0.068 \\
(0.123)\end{array}$ & $\begin{array}{c}1.695 \\
(4.429)\end{array}$ \\
\hline $\mathrm{N}$ & 243 & 243 & 243 & 243 & 243 & 243 & 243 \\
\hline
\end{tabular}

Notes: Heteroskedasticity-robust standard errors clustered by GPA are in parentheses $\left({ }^{*} \mathrm{p}<.10^{* *} \mathrm{p}<.05{ }^{* * *} \mathrm{p}<.01\right)$. Each regression discontinuity estimate in columns 1-4 comes from a local linear model that regresses an indicator for an admission or enrollment outcome on an indicator for being above the GPA threshold of 3.26, distance from that threshold, and the interaction of the two. Columns 5 and 6 contain instrumental variables estimates of the impact of admission on enrollment, where admission has been instrumented with being above the threshold. The sample includes all spring 2014 applicants to OMSCS whose GPA is within 0.5 of the admissions threshold and who belong to the listed subgroup. All regressions control for the gender, race, geography, age, employment and college major variables listed in Table A.1. Enrollment is measured by fall 2016. 
Figure A.1: GPA Distribution, Online Program Applicants

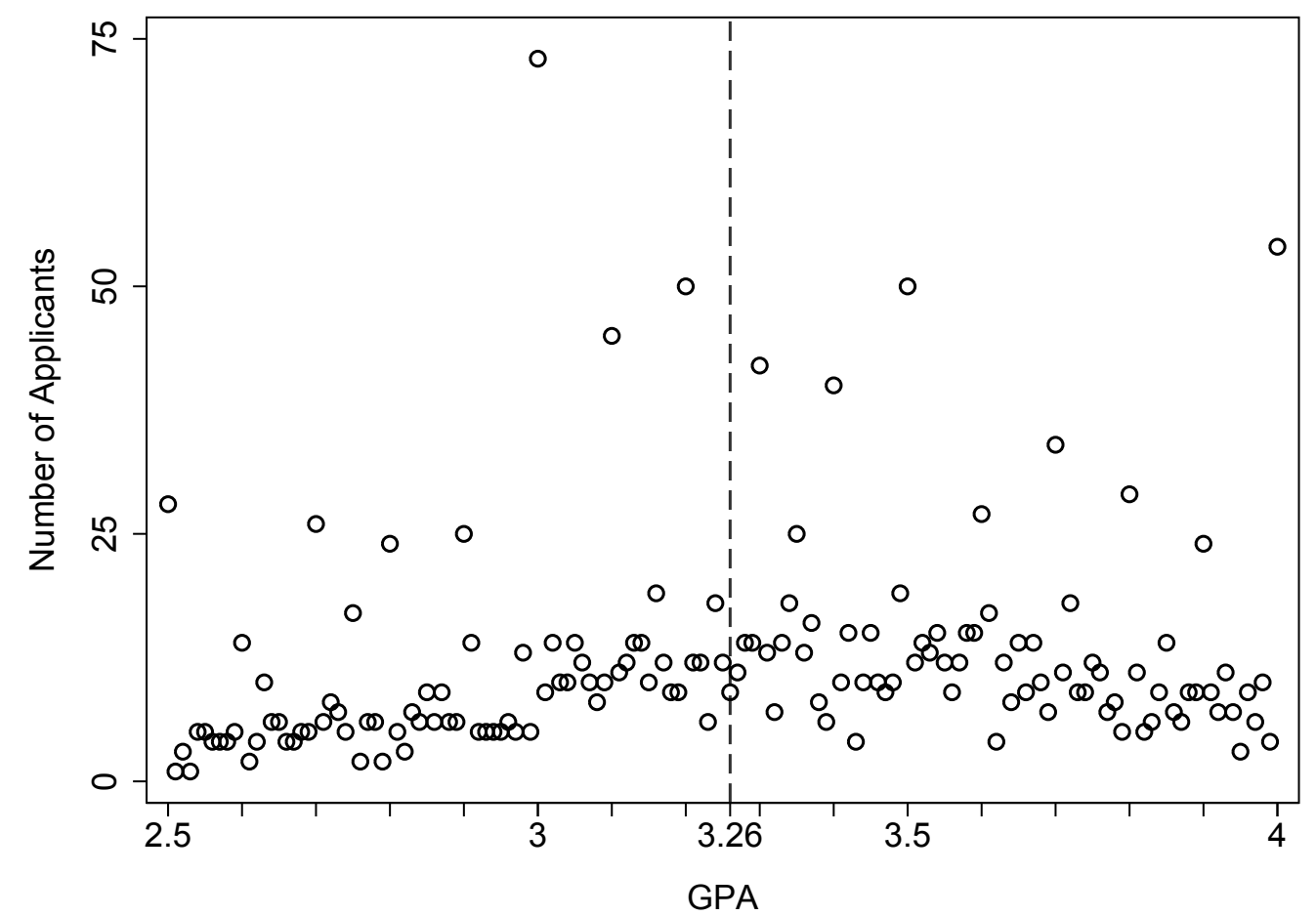

Notes: The above figure shows the number of spring 2014 online program applicants with a given GPA, limiting the sample to those with GPAs between 2.5 and 4.0. 
Figure A.2: Immediate Enrollment in the Online Program

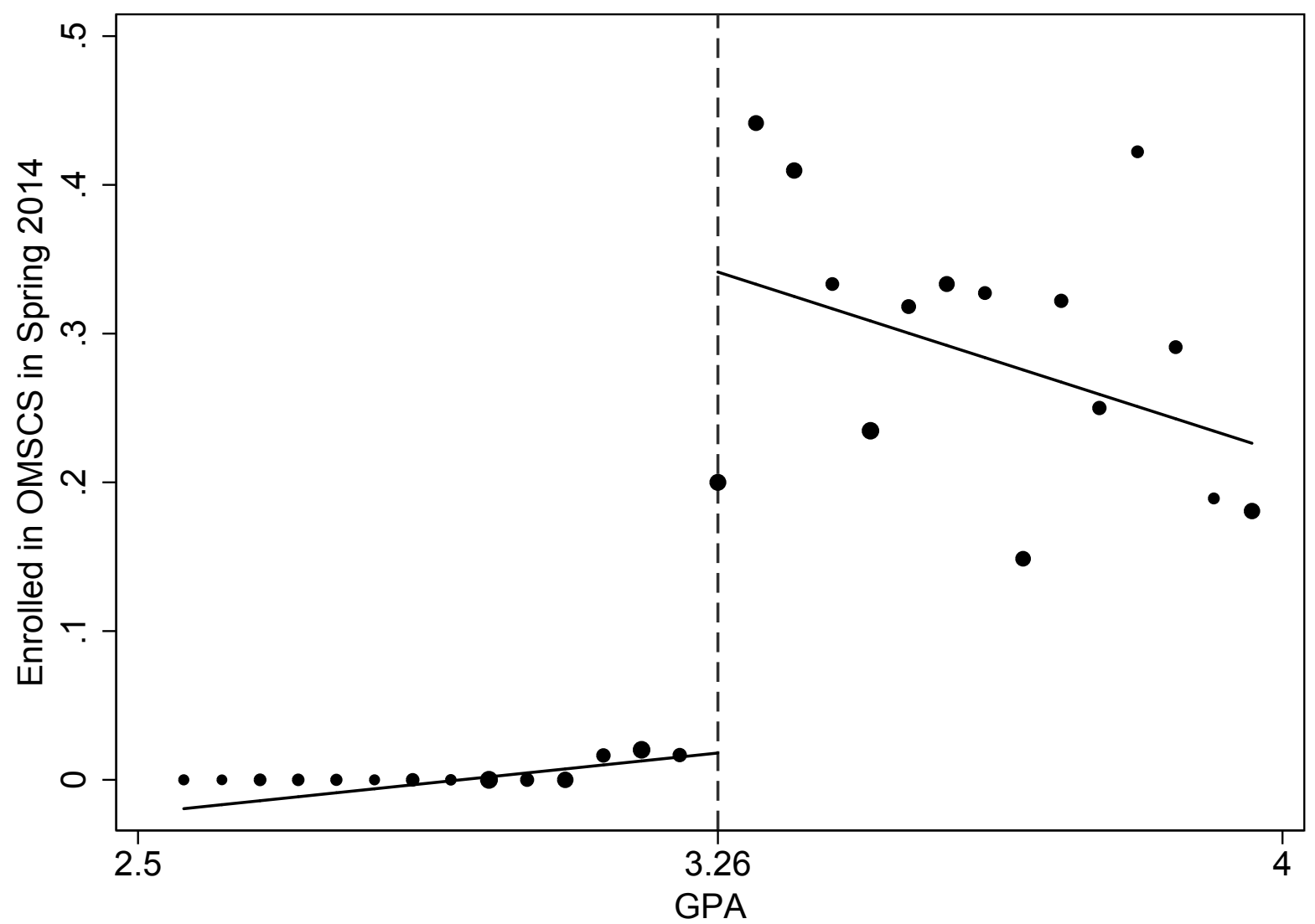

Notes: The above figure shows as a function of college GPA the fraction of spring 2014 online program applicants who enrolled in the online program in spring 2014. The sample is limited to those with GPAs between 2.5 and 4.0. The dots shown come from binning the data in intervals of 0.05 from the threshold, with dot size proportional to the number of applicants in each bin. Also shown are fitted lines from a local linear regression discontinuity model using a bandwidth of 0.5. 
Figure A.3: Enrollment in the Online Program, Conditional on Admission

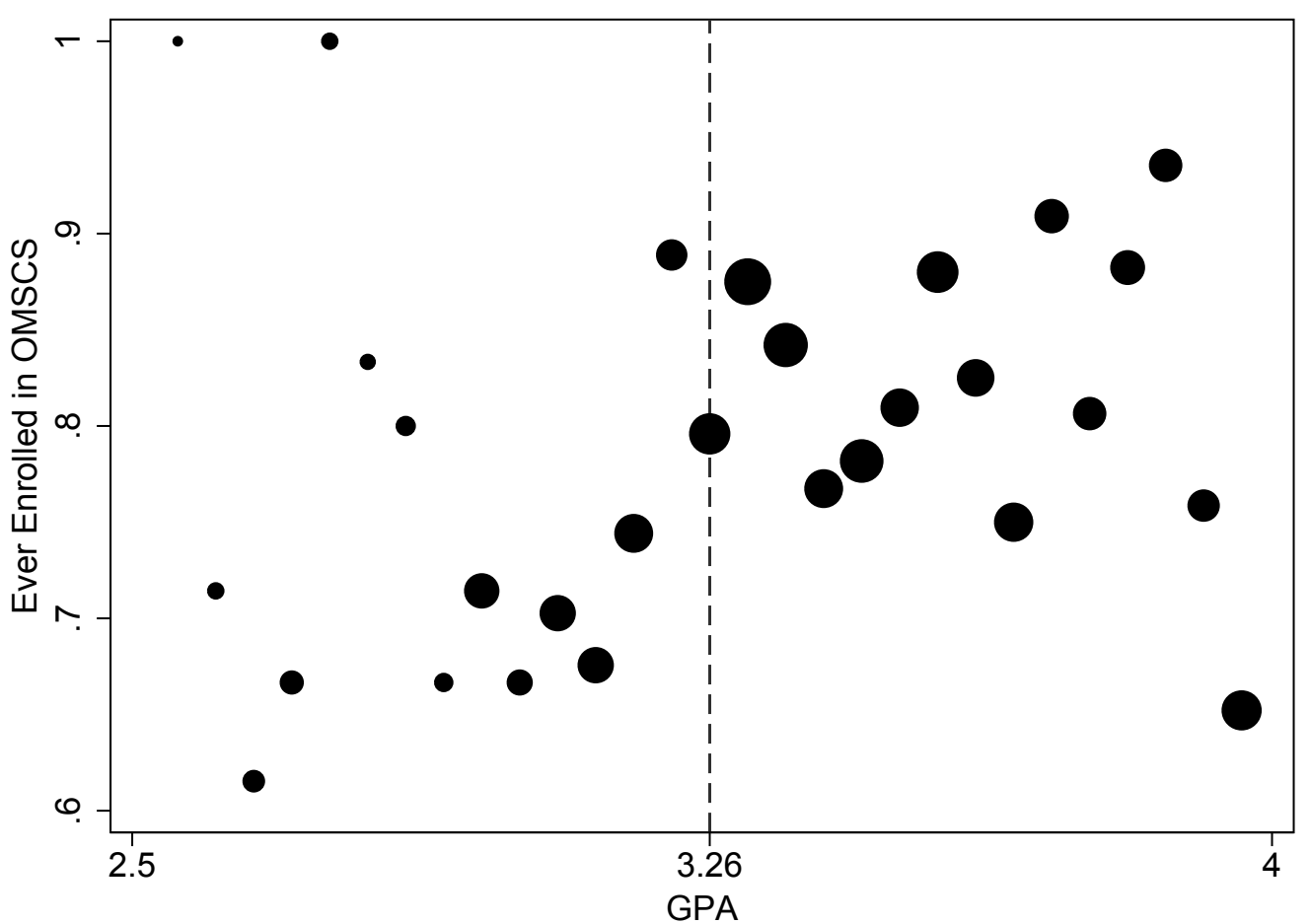

Notes: The above figure shows as a function of college GPA the fraction of spring 2014 online program applicants who were admitted and who enrolled in the online program by fall 2016. The sample is limited to those with GPAs between 2.5 and 4.0. The dots shown come from binning the data in intervals of 0.05 from the threshold, with dot size proportional to the number of applicants in each bin. 
Figure A.4: Placebo and Donut Hole Tests: Admission to the Online Program

(A) Placebo RD

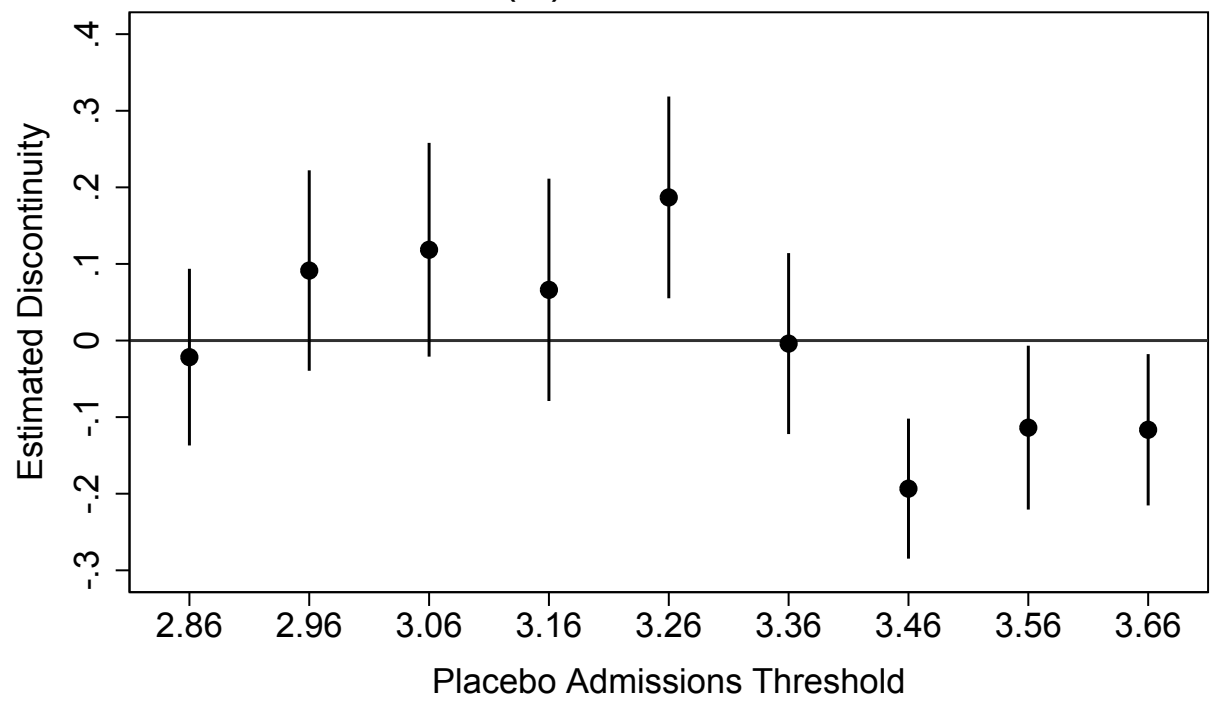

(B) Donut Hole RD

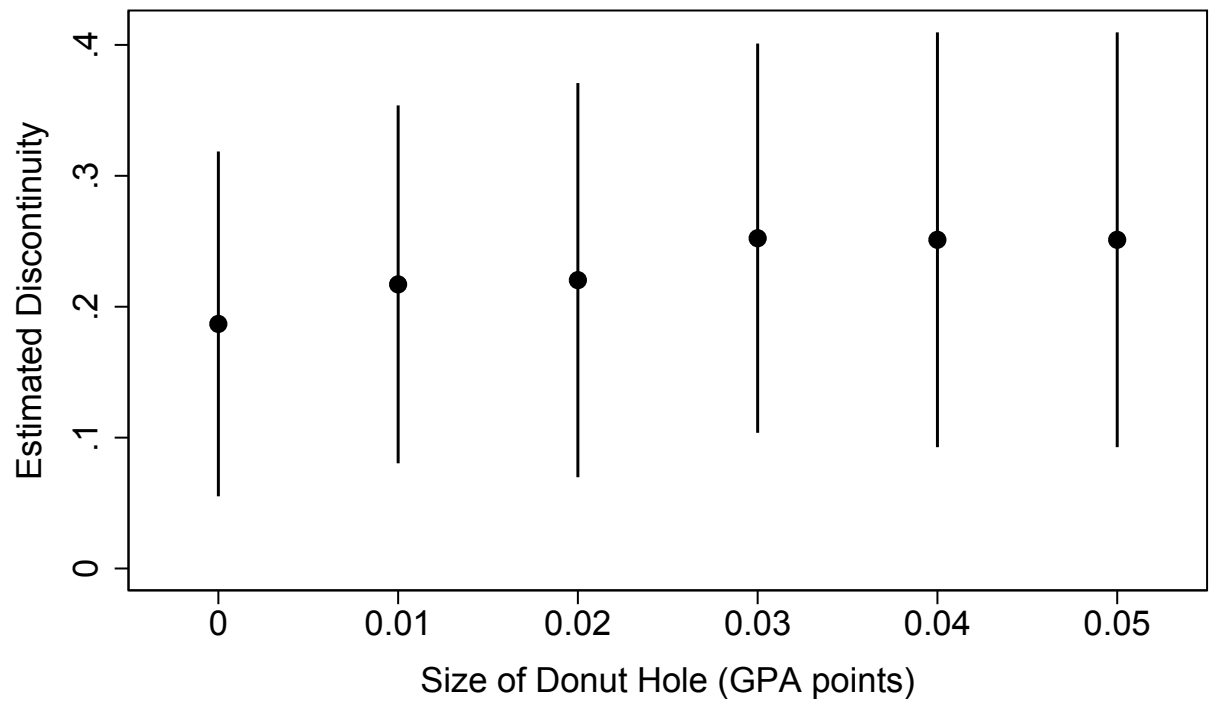

Notes: The outcome in all regressions shown is admission to the online program, for spring 2014 online program applicants. Panel A shows estimated discontinuities from regression specifications that assume the admissions threshold is at the listed GPA value, using a bandwidth of 0.5 GPA points and including demographic controls. Panel B shows estimated discontinuities from regression specifications that assume the correct threshold of 3.26, that use a bandwidth of 0.5 GPA points and include demographic controls, but that exclude applicants whose GPAs are within the listed distance of the threshold. Vertical lines indicate $95 \%$ confidence intervals. 
Figure A.5: Placebo and Donut Hole Tests: Online Enrollment

(A) Placebo RD

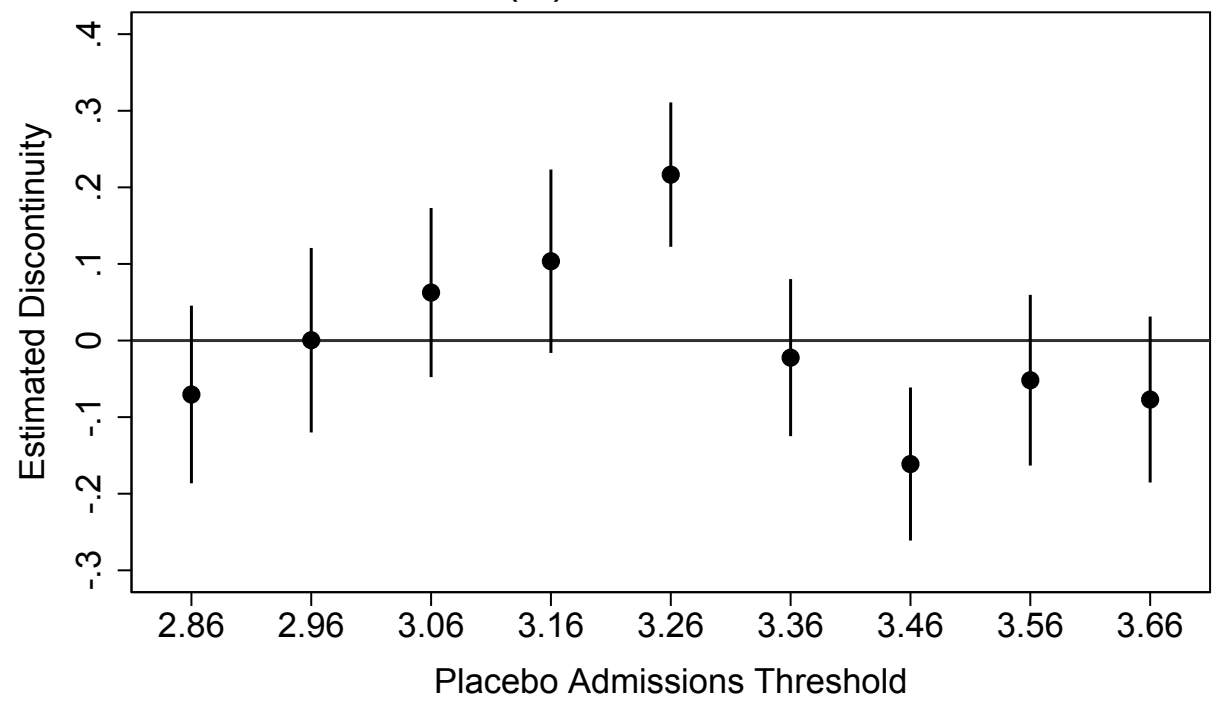

(B) Donut Hole RD

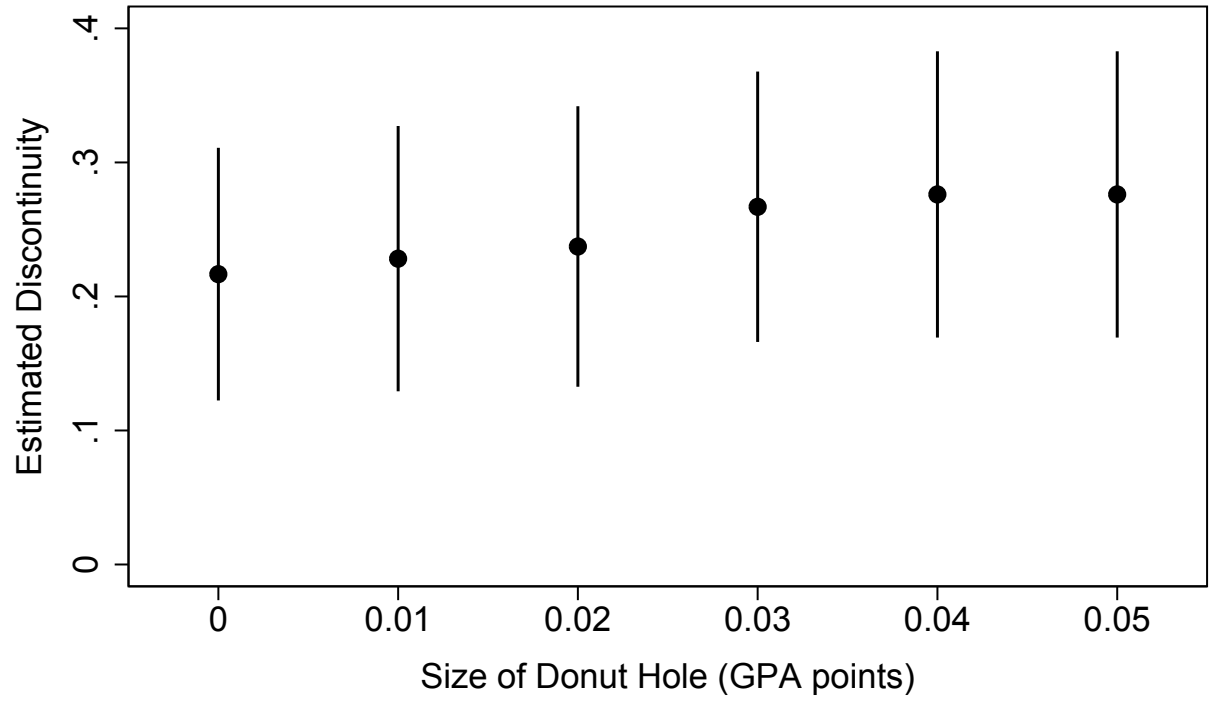

Notes: The outcome in all regressions shown is enrollment in the online program by fall 2016, for spring 2014 online program applicants. Panel A shows estimated discontinuities from regression specifications that assume the admissions threshold is at the listed GPA value, using a bandwidth of 0.5 GPA points and including demographic controls. Panel B shows estimated discontinuities from regression specifications that assume the correct threshold of 3.26, that use a bandwidth of 0.5 GPA points and include demographic controls, but that exclude applicants whose GPAs are within the listed distance of the threshold. Vertical lines indicate 95\% confidence intervals. 
Figure A.6: Placebo and Donut Hole Tests: Enrollment Anywhere

(A) Placebo RD

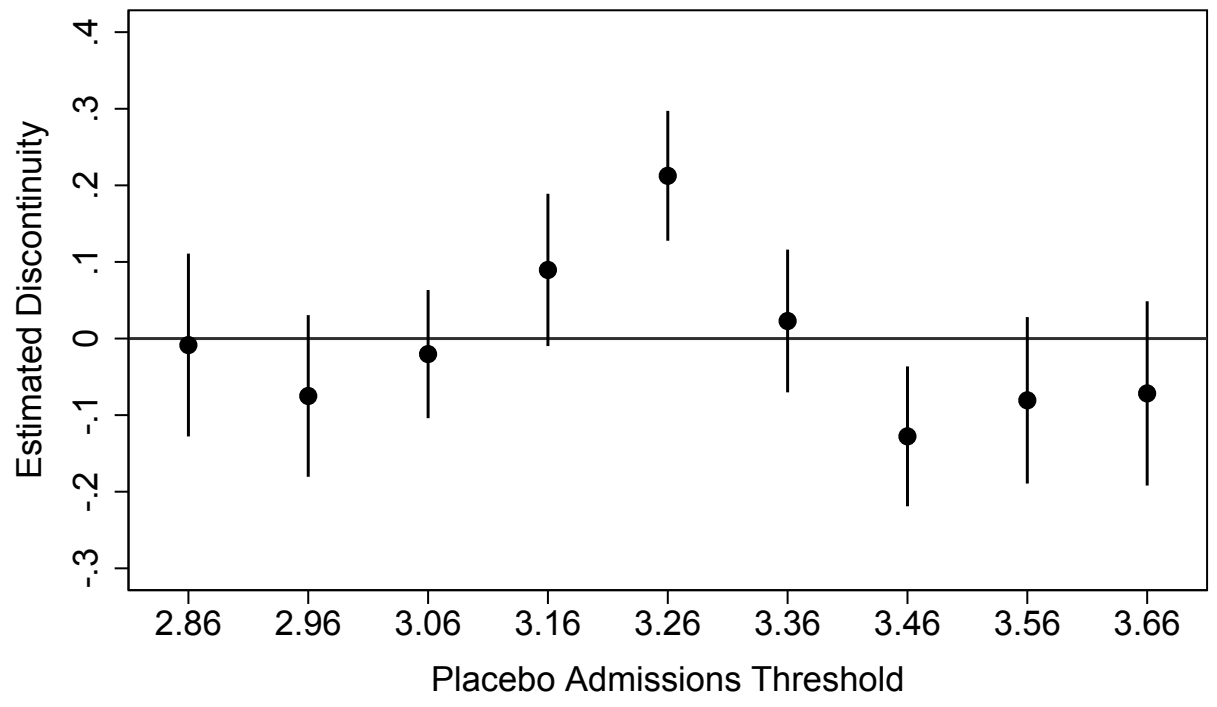

(B) Donut Hole RD

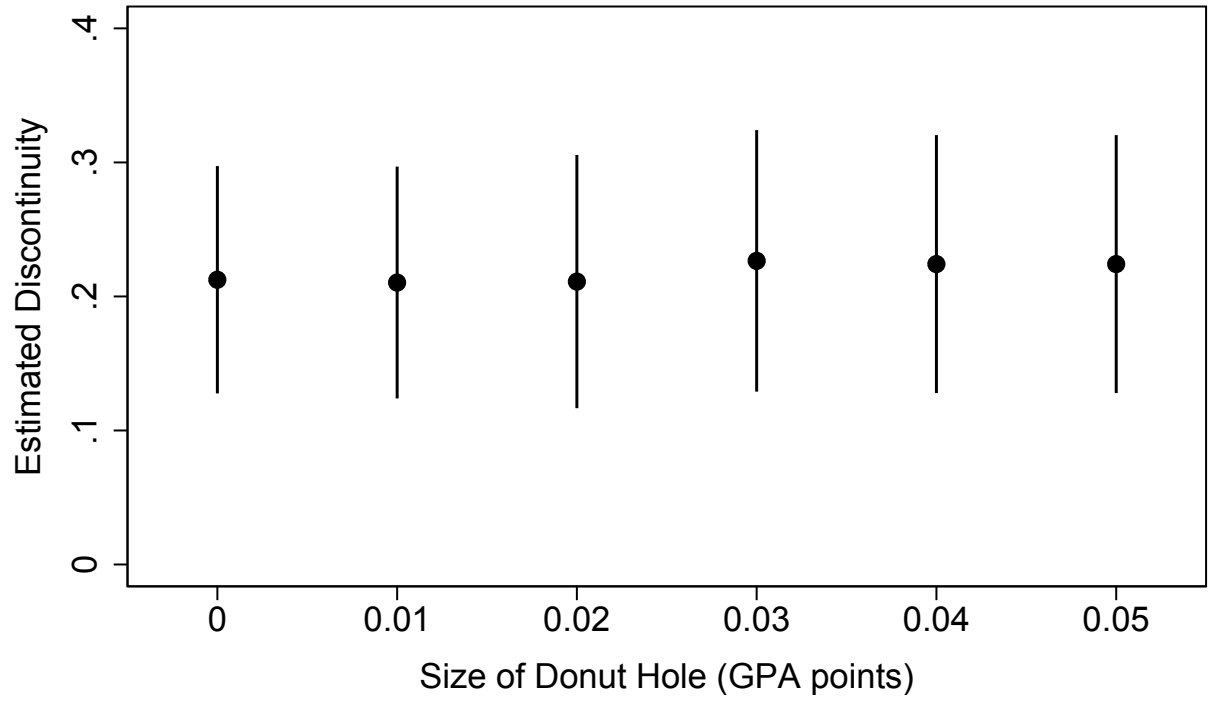

Notes: The outcome in all regressions shown is enrollment in any degree program by fall 2016, for spring 2014 online program applicants. Panel A shows estimated discontinuities from regression specifications that assume the admissions threshold is at the listed GPA value, using a bandwidth of 0.5 GPA points and including demographic controls. Panel B shows estimated discontinuities from regression specifications that assume the correct threshold of 3.26, that use a bandwidth of 0.5 GPA points and include demographic controls, but that exclude applicants whose GPAs are within the listed distance of the threshold. Vertical lines indicate 95\% confidence intervals. 
Table A.1: OMSCS and MSCS Applicant Characteristics by Cohort

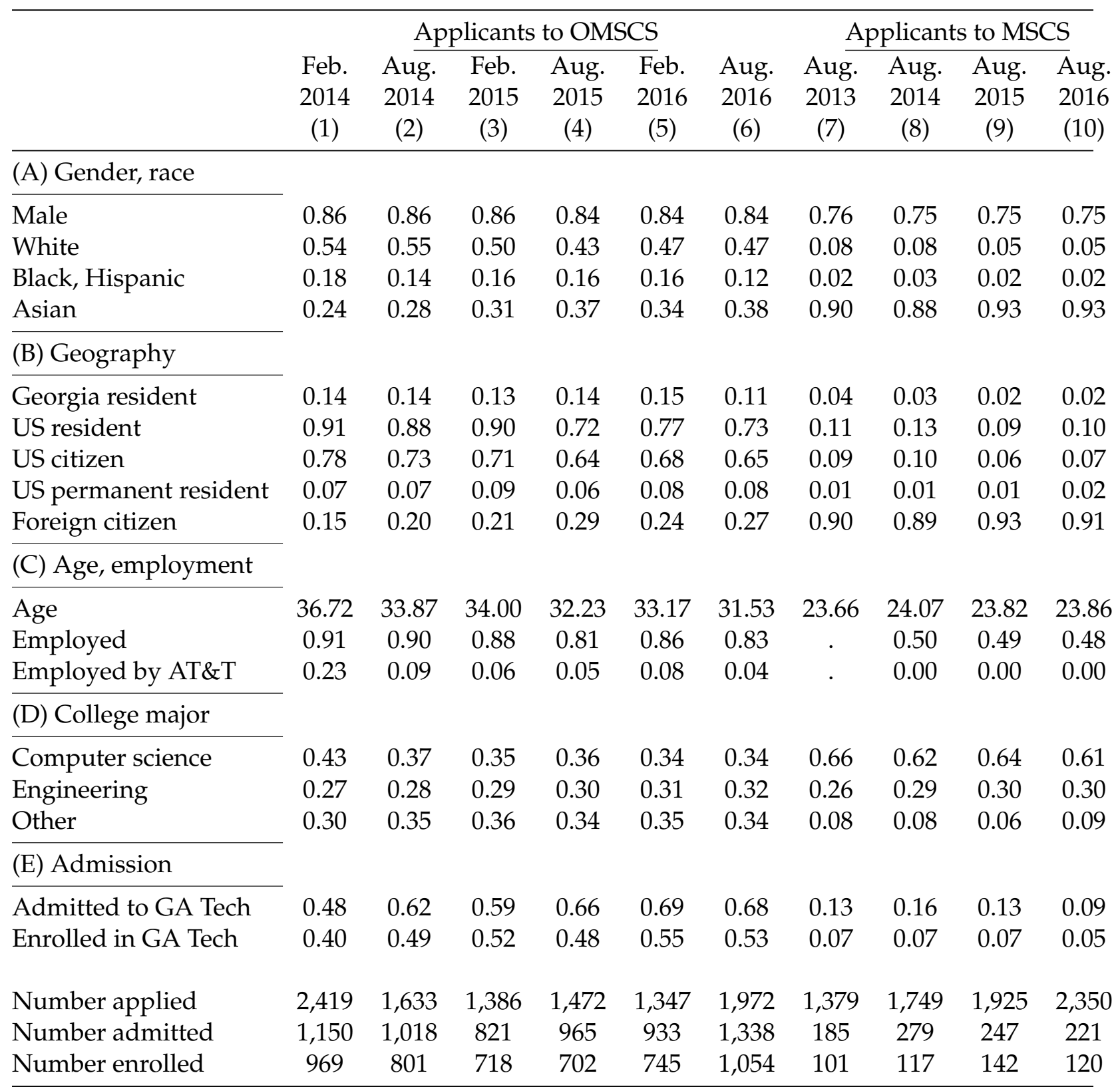

Notes: Listed above are mean values of key variables for applicants to the OMSCS program in columns 1-6 and the MSCS program in columns 7-10. 
Table A.2: Covariate Balance Tests

\begin{tabular}{|c|c|c|c|c|c|c|c|}
\hline & $\begin{array}{c}\text { Male } \\
(1)\end{array}$ & $\begin{array}{c}\text { Asian } \\
(2)\end{array}$ & $\begin{array}{c}\text { Black or } \\
\text { Hispanic } \\
\text { (3) }\end{array}$ & $\begin{array}{c}\text { U.S. } \\
\text { citizen } \\
(4)\end{array}$ & $\begin{array}{l}\text { Age } \\
(5)\end{array}$ & $\begin{array}{c}\text { Employed } \\
\text { (6) }\end{array}$ & $\begin{array}{c}\text { Majored } \\
\text { in CS } \\
(7)\end{array}$ \\
\hline \multicolumn{8}{|l|}{ (A) $\mathrm{BW}=0.7$} \\
\hline Admissible GPA & $\begin{array}{c}0.035 \\
(0.030)\end{array}$ & $\begin{array}{c}0.056^{*} \\
(0.029)\end{array}$ & $\begin{array}{l}-0.026 \\
(0.029)\end{array}$ & $\begin{array}{c}-0.037 \\
(0.031)\end{array}$ & $\begin{array}{c}-1.341 \\
(1.062)\end{array}$ & $\begin{array}{c}-0.004 \\
(0.022)\end{array}$ & $\begin{array}{l}-0.074 \\
(0.062)\end{array}$ \\
\hline $\mathrm{N}$ & 1,706 & 1,706 & 1,706 & 1,706 & 1,706 & 1,706 & 1,706 \\
\hline \multicolumn{8}{|l|}{ (B) $\mathrm{BW}=0.5$} \\
\hline Admissible GPA & $\begin{array}{c}0.031 \\
(0.035)\end{array}$ & $\begin{array}{c}0.050 \\
(0.033)\end{array}$ & $\begin{array}{l}-0.024 \\
(0.033)\end{array}$ & $\begin{array}{c}-0.035 \\
(0.034)\end{array}$ & $\begin{array}{l}-1.929 \\
(1.223)\end{array}$ & $\begin{array}{l}-0.003 \\
(0.027)\end{array}$ & $\begin{array}{c}-0.113 \\
(0.073)\end{array}$ \\
\hline $\mathrm{N}$ & 1,365 & 1,365 & 1,365 & 1,365 & 1,365 & 1,365 & 1,365 \\
\hline \multicolumn{8}{|l|}{ (C) $B W=0.3$} \\
\hline Admissible GPA & $\begin{array}{c}-0.002 \\
(0.049)\end{array}$ & $\begin{array}{c}0.075^{*} \\
(0.040)\end{array}$ & $\begin{array}{l}-0.026 \\
(0.038)\end{array}$ & $\begin{array}{l}-0.069 \\
(0.044)\end{array}$ & $\begin{array}{l}-2.215 \\
(1.596)\end{array}$ & $\begin{array}{l}-0.018 \\
(0.035)\end{array}$ & $\begin{array}{c}-0.128 \\
(0.098)\end{array}$ \\
\hline $\mathrm{N}$ & 926 & 926 & 926 & 926 & 926 & 926 & 926 \\
\hline Control mean & 0.86 & 0.13 & 0.20 & 0.88 & 37.13 & 0.91 & 0.50 \\
\hline
\end{tabular}

Notes: Heteroskedasticity-robust standard errors clustered by GPA are in parentheses $\left.{ }^{*} \mathrm{p}<.10^{* *} \mathrm{p}<.05{ }^{* * *} \mathrm{p}<.01\right)$. Each regression discontinuity estimate comes from a local linear model that regresses the covariate listed on an indicator for being above the GPA threshold, distance from that threshold, and the interaction of the two.The sample includes all spring 2014 applicants to OMSCS whose GPA is within the listed bandwidth. Listed below each column is the mean of the covariate for those 0.01-0.10 GPA points below the threshold. 